\title{
1 Self-assembled nanostructures in ionic liquids facilitate charge 2 storage at electrified interfaces
}

3 Xianwen Mao ${ }^{*}$, Paul Brown ${ }^{1}$, Ctirad Červinka ${ }^{2,3}$, Gavin Hazell ${ }^{4}$, Hua Li ${ }^{5}$, Yinying Ren ${ }^{1}$, Di Chen ${ }^{6}$, Rob

4 Atkin $^{5}$, Julian Eastoe ${ }^{4}$, Isabelle Grillo ${ }^{7}$, Agilio. A. H. Padua ${ }^{1,2}$, Margarida. F. Costa Gomes ${ }^{* 1,2}$, T. Alan

5 Hatton $^{* 1}$

$6{ }^{1}$ Department of Chemical Engineering, Massachusetts Institute of Technology, 77 Massachusetts Avenue, 7 Cambridge, MA, 02139, United States

$8 \quad{ }^{2}$ Ecole Normale Supérieure de Lyon, Laboratoire de Chimie, UMR CNRS 5182, 46 allée d'Italie, 69364 9 Lyon Cedex 07, France

$10 \quad{ }^{3}$ Department of Physical Chemistry, University of Chemistry and Technology, Prague, Technická 5, CZ1116628 Prague 6, Czech Republic

$12{ }^{4}$ School of Chemistry, University of Bristol, Cantock's Close, Bristol BS8 1TS, United Kingdom

$13{ }^{5}$ School of Molecular Sciences, The University of Western Australia, Perth, WA 6009, Australia

$14{ }^{6}$ Department of Materials Science and Engineering, Stanford University, Stanford, CA 94305

$15{ }^{7}$ Institut Max-von-Laue-Paul-Langevin, BP 156-X, F-38042 Grenoble Cedex, France

$16{ }^{*}$ Corresponding author: tahatton@mit.edu (T.A.H.), margarida.costa-gomes@ens-lyon.fr (M.F.C.G.), 17 xmao@mit.edu (X.M.)

\section{ABSTRACT}

Driven by the potential applications of ionic liquids (ILs) in many emerging electrochemical technologies, recent research efforts have been directed at understanding the complex ion ordering in these systems, to uncover novel energy storage mechanisms at IL/electrode interfaces. Here, we discover that surface-active ionic liquids (SAILs), which contain amphiphilic structures inducing self-assembly, exhibit enhanced charge storage performance at electrified surfaces. Unlike conventional nonamphiphilic ILs (NAILs), for which ion distribution is dominated by Coulombic interactions, SAILs exhibit significant and competing van der Waals interactions owing to the nonpolar surfactant tails, leading to unusual interfacial ion distributions. We reveal that at an intermediate degree of electrode polarization SAILs display optimal performance, because the low-charge-density alkyl tails are effectively excluded from the electrode surfaces, whereas the formation of nonpolar domains along the 
surface suppresses undesired overscreening effects. This work represents a crucial step towards understanding the unique interfacial behavior and electrochemical properties of amphiphilic liquid systems showing long-range ordering, and offers insights into the design principles for high-energydensity electrolytes based on spontaneous self-assembly behavior. 5 unique properties such as low volatility and flammability, as well as high electrochemical stability ${ }^{1-5}$. An understanding of the molecular-level interactions between ILs and electrified interfaces is crucial for optimization of device performance ${ }^{6}$. For instance, interfacial IL layers at charged surfaces govern the electric double layer (EDL) structure, a key factor determining the device energy density ${ }^{2,4,6,7}$. The EDL structure with ILs is drastically different from that in aqueous and organic electrolytes ${ }^{8-10}$; the complex ion ordering in ILs exhibits many subtleties, and remains an active area of debate ${ }^{11-14}$. Here we present the first detailed investigation into electrocapacitive characteristics and fundamental EDL structures of an emerging IL class based on surface-active agents, or surface-active ILs (SAILs) ${ }^{13,15-19}$. Our study reveals a novel material design principle for enhancing charge storage owing to the self-assembled nanostructures in amphiphilic liquids, and introduces a class of liquids with long-range ordering, having broad implications for diverse fields, ranging from interfacial science ${ }^{20,21}$ to energy technologies ${ }^{22,23}$.

SAILs are inherently amphiphilic, and can self-assemble into nanostructures composed of distinct polar and nonpolar domains ${ }^{13,15-19}$. Most previous studies on the IL EDL structure and IL-based energy devices focus on non-amphiphilic ILs (NAILs) where neither ion is based on a classical surfactant structure ${ }^{6,24}$. Whereas nanostructuring was observed under confinement for some NAILs where one of the ions, usually the cation, bears moderate to long chains ${ }^{25}$, these nanostructures are weaker - less well defined - than those for SAILs. The bulk phase self-assembled nanostructures of SAILs have been studied previously ${ }^{17}$, but how these nanostructures behave at electrified interfaces and are related to EDL structures, critical for energy storage applications, remains unexplored. Compared to NAILs, SAILs have different properties, which challenge the traditional understanding of IL electrochemistry, as speculated previously ${ }^{26}$. Here we show that at elevated temperatures SAILs impart much higher capacitances than NAILs. Molecular dynamics (MD) simulations reveal that the ion distribution, cation-anion correlations, and decay lengths of molecular layering of SAILs are fundamentally different from those of NAILs. The unusual EDL structure of SAILs stems from their 
unique ability to self-assemble into highly ordered interfacial nanostructures, which is key for producing high capacitances at intermediate electrode polarizations. The energy densities achievable with neat SAILs at elevated temperatures, or of SAIL-NAIL mixtures at room temperature, exceed those of many known electrolytes (Supplementary Note 6), demonstrating adaptability of SAILs for high-energydensity devices. This proof-of-concept work represents a new paradigm for electrochemical energy storage, through exploitation of the unfavorable interactions between hydrocarbon groups and ionic moieties in amphiphilic electrolytes, to drive partitioning of counterions near the interface, and hence, reduce the EDL thicknesses.

\section{Bulk-phase structural and electrochemical characterization}

The SAIL examined here is 1-butyl-3-methylimidazolium 1,4-bis(2-ethylhexoxy)-1,4dioxobutane-2-sulfonate $\left(\left[\mathrm{C}_{4} \mathrm{C}_{1} \mathrm{Im}\right][\mathrm{AOT}]\right)$ (Fig. 1a). [AOT $]^{-}$is distinctly amphiphilic with a negative charge located at one end of the ion (polar head) and a bulky branched di-chain hydrocarbon group at the other end (nonpolar tail). The control IL is a common NAIL, $\left[\mathrm{C}_{4} \mathrm{C}_{1} \mathrm{Im}\right]\left[\mathrm{BF}_{4}\right]$, that contains an identical cation to $\left[\mathrm{C}_{4} \mathrm{C}_{1} \mathrm{Im}\right][\mathrm{AOT}]$ but a smaller, inorganic anion. Temperature-controlled small-angle neutron scattering (SANS) measurements (Fig. 1b) show clearly that $\left[\mathrm{C}_{4} \mathrm{C}_{1} \mathrm{Im}\right][\mathrm{AOT}]$ displays a Bragg peak at $q=0.28^{-1}$, indicating ordered nanostructures with a repeating unit length scale $(d)$ of $\sim 22$, consistent with the expected repeat structure for $\left[\mathrm{C}_{4} \mathrm{C}_{1} \mathrm{Im}\right][\mathrm{AOT}]$ (Fig. $1 \mathrm{~b}$ inset). The SANS is consistent with $[\mathrm{AOT}]^{-}$bilayers formed via aggregation of the nonpolar tails, with charge neutralizing layers of $\left[\mathrm{C}_{4} \mathrm{C}_{1} \mathrm{Im}\right]^{+}$adjacent to the anionic polar heads. The self-assembly of the [AOT] ${ }^{-}$nonpolar tails results in formation of nanoscale nonpolar domains, whereas $\left[\mathrm{C}_{4} \mathrm{C}_{1} \mathrm{Im}\right]^{+}$and the $[\mathrm{AOT}]^{-}$polar heads form polar domains. In contrast, SANS from $\left[\mathrm{C}_{4} \mathrm{C}_{1} \mathrm{Im}\right]\left[\mathrm{BF}_{4}\right]$ does not exhibit a Bragg peak, indicating the absence of any significant long-range ordered nanostructures. Fig. 1c compares the cyclic voltammograms (CVs) of $\left[\mathrm{C}_{4} \mathrm{C}_{1} \mathrm{Im}\right]\left[\mathrm{BF}_{4}\right]$ and $\left[\mathrm{C}_{4} \mathrm{C}_{1} \mathrm{Im}\right][\mathrm{AOT}]$, obtained using supercapacitors composed of carbon nanotubes (CNTs) with a Brunauer-Emmett-Teller (BET) surface area of $198 \mathrm{~m}^{2} / \mathrm{g}$ (Supplementary Fig. 4 a-c). At 25 , the $\mathrm{CV}$ for $\left[\mathrm{C}_{4} \mathrm{C}_{1} \mathrm{Im}\right][\mathrm{AOT}]$ shows a more tilted shape and a smaller integral area than that for $\left[\mathrm{C}_{4} \mathrm{C}_{1} \mathrm{Im}\right]\left[\mathrm{BF}_{4}\right]$. The $\mathrm{CV}$ results suggest a higher ionic resistance and a smaller double-layer capacitance for $\left[\mathrm{C}_{4} \mathrm{C}_{1} \mathrm{Im}\right][\mathrm{AOT}]$, which may be due to its higher viscosity at this temperature (Supplementary Fig. 3c). On increasing temperature the $\mathrm{CV}$ integral areas for both ILs increase, consistent with reduced viscosity. However, unexpectedly, at 130 and 200 , although $\left[\mathrm{C}_{4} \mathrm{C}_{1} \mathrm{Im}\right][\mathrm{AOT}]$ is still more viscous than 
$\left[\mathrm{C}_{4} \mathrm{C}_{1} \operatorname{Im}\right]\left[\mathrm{BF}_{4}\right]$, the $\mathrm{CVs}$ for $\left[\mathrm{C}_{4} \mathrm{C}_{1} \operatorname{Im}\right][\mathrm{AOT}]$ now exhibit significantly larger integral areas than those for $\left[\mathrm{C}_{4} \mathrm{C}_{1} \mathrm{Im}\right]\left[\mathrm{BF}_{4}\right]$. The CV-derived specific capacitances (Fig. 1d) clearly show that at 130 and 200 , $\left[\mathrm{C}_{4} \mathrm{C}_{1} \mathrm{Im}\right][\mathrm{AOT}]$ possesses a remarkably better capacitive energy storage capability than does $\left[\mathrm{C}_{4} \mathrm{C}_{1} \operatorname{Im}\right]\left[\mathrm{BF}_{4}\right]$. Control experiments show that the unusually large capacitances observed for $\left[\mathrm{C}_{4} \mathrm{C}_{1} \mathrm{Im}\right][\mathrm{AOT}]$ do not result from peculiar electrode properties or high-temperature-operation-induced degradation (Supplementary Note 7).

\section{MD simulations reveal anomalous EDL structures in SAILs}

The observed differences in electrocapacitive performance between $\left[\mathrm{C}_{4} \mathrm{C}_{1} \mathrm{Im}\right][\mathrm{AOT}]$ and $\left[\mathrm{C}_{4} \mathrm{C}_{1} \mathrm{Im}\right]\left[\mathrm{BF}_{4}\right]$ may stem from their distinct molecular architectures, leading to different EDL structures. To understand why $\left[\mathrm{C}_{4} \mathrm{C}_{1} \mathrm{Im}\right][\mathrm{AOT}]$ outperforms $\left[\mathrm{C}_{4} \mathrm{C}_{1} \mathrm{Im}\right]\left[\mathrm{BF}_{4}\right]$ at higher temperatures, we interrogated the detailed EDL structures of the two ILs, confined by electrified graphite surfaces at elevated temperature, via atomistic molecular dynamics (MD) simulations (details in Methods and Supplementary Note 4.1). Fig. 2 a and c show the ion number density ( $\rho_{\mathrm{N}}$, normalized to the bulk value) profiles of $\left[\mathrm{C}_{4} \mathrm{C}_{1} \mathrm{Im}\right]\left[\mathrm{BF}_{4}\right]$ and $\left[\mathrm{C}_{4} \mathrm{C}_{1} \mathrm{Im}\right][\mathrm{AOT}]$, respectively, at electrified interfaces with applied potentials $(U)$ of $\pm 2 \mathrm{~V}$. The NAIL $\left[\mathrm{C}_{4} \mathrm{C}_{1} \mathrm{Im}\right]\left[\mathrm{BF}_{4}\right]$ exhibits a lamellar structure of alternating charges, which persists for $\sim$ eight ion layers (4 distinguishable maxima for cation and anion $\rho_{\mathrm{N}}$ profiles), consistent with previous experimenta ${ }^{11}$ and theoretical ${ }^{27}$ observations of charged-surface-induced longrange molecular layering in common NAILs. Interestingly, $\left[\mathrm{C}_{4} \mathrm{C}_{1} \mathrm{Im}\right][\mathrm{AOT}]$ displays a different molecular layering behavior: the surface induced charge-alternating structure for $\left[\mathrm{C}_{4} \mathrm{C}_{1} \operatorname{Im}\right][\mathrm{AOT}]$ only persists for $\sim$ two ion layers, with the first peak showing a much larger $\rho_{\mathrm{N}}$ relative to that of $\left[\mathrm{C}_{4} \mathrm{C}_{1} \operatorname{Im}\right]\left[\mathrm{BF}_{4}\right]$. Notably, the simulated static neutron scattering structure factors for $\left[\mathrm{C}_{4} \mathrm{C}_{1} \operatorname{Im}\right][\mathrm{AOT}]$ and $\left[\mathrm{C}_{4} \mathrm{C}_{1} \mathrm{Im}\right]\left[\mathrm{BF}_{4}\right]$ (Supplementary Fig. 11, Supplementary Note 4.1) match their respective SANS profiles (Fig. 1b)

The nanoscale self-assembly of the nonpolar groups in $\left[\mathrm{C}_{4} \mathrm{C}_{1} \mathrm{Im}\right][\mathrm{AOT}]$ may account for the atypical ion packing behavior at electrified interfaces (Fig. 2 c-d), being in stark contrast to the conventional behavior of NAILs (Fig. 2 a-b). At neutral interfaces, the bulk microscopic structure of $\left[\mathrm{C}_{4} \mathrm{C}_{1} \mathrm{Im}\right][\mathrm{AOT}]$ is characterized by the formation of charged polar domains and nonpolar domains (Fig. $1 \mathrm{~b}$ inset). Introduction of surface charges then induce alignment of charged domains along the interface. Near a positively charged surface, the polar heads of $[\mathrm{AOT}]^{-}$are electrostatically attracted to the 
interface, whereas the nonpolar tails orientate outward, in close proximity to the nonpolar tails of the next $[\mathrm{AOT}]^{-}$layer, thus forming a bilayer parallel to the positively charged surface, with a neutralizing $\left[\mathrm{C}_{4} \mathrm{C}_{1} \mathrm{Im}\right]^{+}$layer adjacent to the anionic polar heads of $[\mathrm{AOT}]^{-}$. At a negatively charged surface, the innermost ion layer is enriched in $\left[\mathrm{C}_{4} \mathrm{C}_{1} \mathrm{Im}\right]^{+}$cations which fully neutralize the adjacent anionic [AOT $]^{-}$ bilayer (i.e., the presence of an $[\mathrm{AOT}]^{-}$bilayer squeezes excess cations into the first ion layer near the interface). The ability to pack excess ions at charged interfaces is an advantageous feature of SAILs compared to NAILs, and is driven by the unfavorable interaction between the hydrocarbon and ionic groups compared to cation-anion interactions. Another unexpected finding for $\left[\mathrm{C}_{4} \mathrm{C}_{1} \mathrm{Im}\right][\mathrm{AOT}]$ is that the cation and anion $\rho_{\mathrm{N}}$ profiles beyond the first two ion layers are positively correlated (Fig. 2e, right panel), possibly due to the co-movement of $\left[\mathrm{C}_{4} \mathrm{C}_{1} \mathrm{Im}\right]^{+}$cations and [AOT] $]^{-}$polar heads. The nonpolar tail-tail interaction could lead to the confinement of small $\left[\mathrm{C}_{4} \mathrm{C}_{1} \mathrm{Im}\right]^{+}$cations and $[\mathrm{AOT}]^{-}$polar heads within the polar domains. With short-alkyl-chain NAILs, which cannot self-assemble, the ion-ion electrostatic interactions alone dictate that the anionic density reaches a maximum where the cationic density reaches a minimum, which should result in negatively-correlated anion-cation spatial distributions (Fig. 2e, left panel).

The ability of $\left[\mathrm{C}_{4} \mathrm{C}_{1} \mathrm{Im}\right][\mathrm{AOT}]$ to pack excess ions at the interface and the positive correlation between the cation and anion spatial distribution suggests that $\left[\mathrm{C}_{4} \mathrm{C}_{1} \mathrm{Im}\right][\mathrm{AOT}]$ should reach bulk electroneutrality over shorter distances than $\left[\mathrm{C}_{4} \mathrm{C}_{1} \mathrm{Im}\right]\left[\mathrm{BF}_{4}\right]$, which can be validated by calculating the net charge density $\left(\rho_{\mathrm{Q}}\right)$ distributions (Fig. 2f). The NAIL $\left[\mathrm{C}_{4} \mathrm{C}_{1} \mathrm{Im}\right]\left[\mathrm{BF}_{4}\right]$ shows a pronounced $\rho_{\mathrm{Q}}$ oscillatory pattern before reaching electroneutrality at around 30 from the surface. In contrast, the amplitude of $\rho_{\mathrm{Q}}$ oscillation for $\left[\mathrm{C}_{4} \mathrm{C}_{1} \mathrm{Im}\right][\mathrm{AOT}]$ diminishes more quickly, and decays to its bulk value around 10 from the surface. The decay length $(\xi)$ of the charge oscillation, quantified using an envelope function that confines the $\rho_{\mathrm{Q}}$ profile (Supplementary Note 4.2), is shown in Fig. $2 \mathrm{~g}$ as a function of $U$. Compared to $\left[\mathrm{C}_{4} \mathrm{C}_{1} \mathrm{Im}\right]\left[\mathrm{BF}_{4}\right],\left[\mathrm{C}_{4} \mathrm{C}_{1} \mathrm{Im}\right][\mathrm{AOT}]$ generally exhibits smaller $\xi$ values, indicating thinner EDLs and thus larger capacitances. The calculated differential capacitances $\left(C_{\mathrm{d}}\right)($ Fig. 2h; Supplementary Note 4.2) show that with intermediate electrode polarization (i.e., $1 \mathrm{~V}<|U|<2 \mathrm{~V}$ ) $\left[\mathrm{C}_{4} \mathrm{C}_{1} \mathrm{Im}\right][\mathrm{AOT}]$ generally exhibits higher differential capacitances than does $\left[\mathrm{C}_{4} \mathrm{C}_{1} \mathrm{Im}\right]\left[\mathrm{BF}_{4}\right]$. However, at low electrode polarization (i.e, $U$ is near $0 \mathrm{~V}$ ), $\left[\mathrm{C}_{4} \mathrm{C}_{1} \mathrm{Im}\right][\mathrm{AOT}]$ shows lower capacitances than $\left[\mathrm{C}_{4} \mathrm{C}_{1} \mathrm{Im}\right]\left[\mathrm{BF}_{4}\right]$, probably because near the electrode surface the former has a larger density of [AOT] nonpolar tails (i.e., latent voids), reducing the near-surface charge density (Supplementary Fig. 12). By contrast, at intermediate polarization (i.e., $|U|$ is about 1 to $2 \mathrm{~V}$ ), those nonpolar tails do not partition to 
151 the electrode surface (Supplementary Fig. 12), resulting in $\sim 22$ wide nonpolar domains parallel to the 152 electrode surface. This prevents the development of strongly oscillating, cation-anion alternating 153 structure, commonly observed in NAILs, that would lead to overscreening and EDL thickening. The role 154 of such nonpolar domains in preventing overscreening effects may be analogous to that played by a 155 second electrode wall inside a nanopore ${ }^{28}$. The potential-dependent rearrangement of the [AOT] 156 nonpolar tails, revealed by these atomistic MD simulations, agrees with earlier studies based on Monte 157 Carlo simulations of liquids with elongated ions containing charged "heads" and neutral "tails"29,30. At 158 high electrode polarization (i.e., $|U|>2 \mathrm{~V}$ ), lattice saturation effects due to the steric constraints of finite 159 ion sizes ${ }^{6,7}$ occur, and the capacitances of both $\left[\mathrm{C}_{4} \mathrm{C}_{1} \operatorname{Im}\right][\mathrm{AOT}]$ and $\left[\mathrm{C}_{4} \mathrm{C}_{1} \operatorname{Im}\right]\left[\mathrm{BF}_{4}\right]$ will decrease. 160 Additionally, the thinner EDL (and thus shorter Debye length) for $\left[\mathrm{C}_{4} \mathrm{C}_{1} \mathrm{Im}\right][\mathrm{AOT}]$ relative to that of $161\left[\mathrm{C}_{4} \mathrm{C}_{1} \mathrm{Im}\right]\left[\mathrm{BF}_{4}\right]$ at intermediate electrode polarization implies a higher free ion concentration in the 162 former. In the EDL of $\left[\mathrm{C}_{4} \mathrm{C}_{1} \mathrm{Im}\right]\left[\mathrm{BF}_{4}\right]$, as in other NAILs ${ }^{8,10}$, most cations and anions are strongly 163 associated to form "neutral aggregates" (Fig. 2b) which contribute weakly to the free ion concentration. 164 By contrast, in the EDL of $\left[\mathrm{C}_{4} \mathrm{C}_{1} \mathrm{Im}\right][\mathrm{AOT}]$, due to its amphiphilic nature, only half the population of the 165 first counterion layer could form neutral aggregates with the neighboring co-ion layer, resulting in 166 abundant free counter-ions at the interface (Fig. 2d). Additional constant-surface-charge simulations 167 (Supplementary Fig. 7) yielded consistent results with those shown here by the constant-surface168 potential method (Fig. 2).

\section{Elucidation of interfacial nanostructures by atomic force microscopy}

Atomic force microscopy (AFM) measurements were performed to examine the nanoscale molecular layering of these ionic liquids at a graphite electrode (for experimental details, see Methods and Supplementary Note 5). It is recognized that ionic liquids form layered structures near solid surfaces, which are referred to as interfacial nanostructures ${ }^{31-35}$. The AFM force-distance profiles for $\left[\mathrm{C}_{4} \mathrm{C}_{1} \mathrm{Im}\right]\left[\mathrm{BF}_{4}\right]$ and $\left[\mathrm{C}_{4} \mathrm{C}_{1} \mathrm{Im}\right][\mathrm{AOT}]$ (Fig. 3) consist of a series of pronounced, discrete steps, produced by the AFM tip pushing up against, and then rupturing, interfacial layers. The "rupture force" for an IL layer is reflected by the maximum of each step; a larger rupture force indicates a higher degree of ordering (i.e., stronger cohesive interactions) in the ion layer. For both ILs, at the open circuit potential (OCP), the data reveal only two steps with small rupture forces, indicating weak interfacial structures, whereas with applied biases $(\mathrm{OCP} \pm 1 \mathrm{~V})$ at least four steps are seen, with much higher rupture forces, 
181 indicating stronger ordering of interfacial nanostructures. Additionally, for all the three cases (at OCP, 182 OCP $-1 \mathrm{~V}$ and OCP $+1 \mathrm{~V}$ ), the rupture force decreases more rapidly with layer number for $183\left[\mathrm{C}_{4} \mathrm{C}_{1} \mathrm{Im}\right][\mathrm{AOT}]$ than $\left[\mathrm{C}_{4} \mathrm{C}_{1} \mathrm{Im}\right]\left[\mathrm{BF}_{4}\right]$, which matches well the simulations described above (Fig. 2 a and $184 \mathrm{c})$. Moreover, the rupture force for step $\mathrm{I}$ is higher for $\left[\mathrm{C}_{4} \mathrm{C}_{1} \mathrm{Im}\right][\mathrm{AOT}]$ than for $\left[\mathrm{C}_{4} \mathrm{C}_{1} \operatorname{Im}\right]\left[\mathrm{BF}_{4}\right]$, again 185 consistent with the simulations (Fig. 2 a and c) showing that $\rho_{\mathrm{N}}$ of the innermost layer is much larger for $\left[\mathrm{C}_{4} \mathrm{C}_{1} \mathrm{Im}\right][\mathrm{AOT}]$ than for $\left[\mathrm{C}_{4} \mathrm{C}_{1} \mathrm{Im}\right]\left[\mathrm{BF}_{4}\right]$.

The separation between two adjacent steps (i.e., between steps I/II, II/III, or III/IV shown in Fig. 3) for $\left[\mathrm{C}_{4} \mathrm{C}_{1} \mathrm{Im}\right]\left[\mathrm{BF}_{4}\right]$ and $\left[\mathrm{C}_{4} \mathrm{C}_{1} \mathrm{Im}\right][\mathrm{AOT}]$ is notably different. For $\left[\mathrm{C}_{4} \mathrm{C}_{1} \mathrm{Im}\right]\left[\mathrm{BF}_{4}\right]$ the separation is 6-7 $\AA$ (corresponding to the physical dimension of an ion pair of $\left[\mathrm{C}_{4} \mathrm{C}_{1} \mathrm{Im}\right]^{+}$and $\left[\mathrm{BF}_{4}\right]^{-}$), in accordance with the MD simulations (Fig. 2a, schematically illustrated by orange double arrows in Fig. 2b). In stark contrast, the separation between steps for $\left[\mathrm{C}_{4} \mathrm{C}_{1} \mathrm{Im}\right][\mathrm{AOT}]$ is three to four times larger $(22-24 \AA)$, in good agreement with both the repeating unit length scale measured by SANS (Fig. 1b) and the simulations (Fig. 2c, schematically illustrated by orange double arrows in Fig. 2d). For $\left[\mathrm{C}_{4} \mathrm{C}_{1} \operatorname{Im}\right]\left[\mathrm{BF}_{4}\right]$, with applied biases of $\pm 1 \mathrm{~V}$, the separation between the electrode surface and step I (corresponding to the layer nearest to the surface) is about 2-3 $\AA$, indicating a single ion layer (either cation or anion, depending on the applied bias, as shown by the green double arrow in Fig. 2b). This agrees well with the simulated ion number density profiles, indicating the first ion layer is about 2-3 $\AA$ thick (Fig. 2a). For $\left[\mathrm{C}_{4} \mathrm{C}_{1} \mathrm{Im}\right][\mathrm{AOT}]$, at OCP $-1 \mathrm{~V}$, the separation between the electrode surface and step I is about $4 \AA$, corresponding to a cation-rich layer, also consistent with the simulations (Fig. 2c, left; green double arrow in Fig. 2d, left). For $\left[\mathrm{C}_{4} \mathrm{C}_{1} \mathrm{Im}\right][\mathrm{AOT}]$ at $\mathrm{OCP}+1 \mathrm{~V}$, step $\mathrm{I}$ is about $6 \AA$ thick, consistent with simulations (Fig 2c, right; green double arrow in Fig. 2d, right), but much smaller than the distance expected for an $[\mathrm{AOT}]^{-}$double layer. This is a consequence of the $[\mathrm{AOT}]^{-}$neutral tails tending to orientate towards the electrode surface through solvophobic interactions (Supplementary Fig. 12). These force measurements unambiguously confirm the fundamentally different interfacial nanostructures between $\left[\mathrm{C}_{4} \mathrm{C}_{1} \mathrm{Im}\right][\mathrm{AOT}]$ and $\left[\mathrm{C}_{4} \mathrm{C}_{1} \mathrm{Im}\right]\left[\mathrm{BF}_{4}\right]$ as suggested by the MD simulations. While high-energy $\mathrm{x}-$ ray reflectivity (XRR) measurements may be used to elucidate interfacial nanostructures of ionic liquids $^{11}$, we could not obtain good XRR signals for our IL systems, possibly due to the difficulty of preparing a thin, uniform IL film with high stability under x-ray exposure (Supplementary Note 5).

\section{EDL properties probed by impedance measurements}


To further examine how the EDL capacitances of $\left[\mathrm{C}_{4} \mathrm{C}_{1} \mathrm{Im}\right][\mathrm{AOT}]$ and $\left[\mathrm{C}_{4} \mathrm{C}_{1} \mathrm{Im}\right]\left[\mathrm{BF}_{4}\right]$ vary with applied potential, impedance measurements (Methods and Supplementary Note 3) were performed to obtain the differential capacitance versus potential profile for both ILs (Fig. 4), using a glassy carbon electrode consisting of a flat IL/graphite interface. With increasing temperature, the capacitances of both ILs become larger consistent with decreasing viscosities, in accordance with the $\mathrm{CV}$ measurements in a supercapacitor device (Fig. 1d). More importantly, the capacitance curve of $\left[\mathrm{C}_{4} \mathrm{C}_{1} \mathrm{Im}\right][\mathrm{AOT}]$ is characterized by a minimum at small $|U|$ and two maxima at intermediate $|U|$, whereas that for $\left[\mathrm{C}_{4} \mathrm{C}_{1} \mathrm{Im}\right]\left[\mathrm{BF}_{4}\right]$ exhibits a bell-like shape. These capacitance profiles for $\left[\mathrm{C}_{4} \mathrm{C}_{1} \mathrm{Im}\right][\mathrm{AOT}]$ and $\left[\mathrm{C}_{4} \mathrm{C}_{1} \mathrm{Im}\right]\left[\mathrm{BF}_{4}\right]$ agree generally with the simulations (Fig. 2h), re-emphasizing fundamental differences in the EDL structures between SAILs and NAILs. Certain fine features, such as the exact positions of minima and maxima in the capacitance curves differ between the simulations and experimental data, possibly due to factors such as specific adsorption or local dielectric properties which are not accurately captured by the simulations. Notably, the experimentally measured capacitances here are not dictated by the quantum capacitances of the carbon electrodes employed, and reflect faithfully the EDL capacitances of the ionic liquids investigated (Supplementary Note 8 ).

\section{Generality, applicability and limitations of SAILs}

We simulated the EDL structures of two other SAILs sharing the same $\left[\mathrm{C}_{4} \mathrm{C}_{1} \mathrm{Im}\right]^{+}$cation as $\left[\mathrm{C}_{4} \mathrm{C}_{1} \mathrm{Im}\right][\mathrm{AOT}]$, but with different anions: dodecylsulfonate ([DDS $]^{-}$single-chain surfactant anion) and 1,5-bis(hexyloxy)-3-((hexyloxy)carbonyl)-1,5-dioxopentane-2-sulfonate ([TC $]^{-}$tri-chain surfactant anion) (Fig. 5a). These other SAILs show significant structural variations compared to $[\mathrm{AOT}]]^{-}$. The simulations indicate that, compared to $\left[\mathrm{C}_{4} \mathrm{C}_{1} \mathrm{Im}\right]\left[\mathrm{BF}_{4}\right]$, both $\left[\mathrm{C}_{4} \mathrm{C}_{1} \mathrm{Im}\right][\mathrm{DDS}]$ and $\left[\mathrm{C}_{4} \mathrm{C}_{1} \mathrm{Im}\right][\mathrm{TC}]$ also exhibit diminished $\rho_{\mathrm{Q}}$ oscillations (Fig. 5b) and a thinner EDLs (Fig. 5c) at intermediate electrode polarizations (i.e., surface charge density $\sigma= \pm 5$ and $\pm 10 \mu \mathrm{C} / \mathrm{cm}^{2}$ ), suggesting that these may be generic features of SAILs. To validate that MD captures the self-assembly behavior shown by SANS, additional simulations were performed using uncharged confining surfaces at a lower temperature of 100 . Such conditions allow for the study of SAIL structures in the absence of an electric field, and with suppressed thermal fluctuations, so that the nonpolar domains align parallel to the confining surface (Fig. 5d, left) instead of assuming random orientations (Fig. 5d, right). Therefore, the repeating structures of SAILs along the $z$-axis normal to the interface can be visualized directly. Fig. 5e shows 
clearly that the three SAILs, $\left[\mathrm{C}_{4} \mathrm{C}_{1} \mathrm{Im}\right][\mathrm{DDS}],\left[\mathrm{C}_{4} \mathrm{C}_{1} \mathrm{Im}\right][\mathrm{AOT}]$ and $\left[\mathrm{C}_{4} \mathrm{C}_{1} \mathrm{Im}\right][\mathrm{TC}]$, display a periodic $\rho_{\mathrm{N}}$ pattern reflecting their repeating nanostructures, lacked by the profile for $\left[\mathrm{C}_{4} \mathrm{C}_{1} \mathrm{Im}\right]\left[\mathrm{BF}_{4}\right]$. The average peak spacing in the $\rho_{\mathrm{N}}$ patterns appears to decrease from $\left[\mathrm{C}_{4} \mathrm{C}_{1} \mathrm{Im}\right][\mathrm{DDS}]$ to $\left[\mathrm{C}_{4} \mathrm{C}_{1} \mathrm{Im}\right][\mathrm{AOT}]$ to $\left[\mathrm{C}_{4} \mathrm{C}_{1} \mathrm{Im}\right][\mathrm{TC}]$, consistent with the reduction in anion size/length ([DDS $]^{-}>[\mathrm{AOT}]^{-}>[\mathrm{TC}]^{-}$) as well as the decreasing characteristic length of repeating structures measured by small-angle X-ray scattering $\left(\left[\mathrm{C}_{4} \mathrm{C}_{1} \mathrm{Im}\right][\mathrm{DDS}]=22.9 \quad,\left[\mathrm{C}_{4} \mathrm{C}_{1} \mathrm{Im}\right][\mathrm{AOT}]=21.5 \quad,\left[\mathrm{C}_{4} \mathrm{C}_{1} \mathrm{Im}\right][\mathrm{TC}]=18.8 \quad\right)^{19}$.

To validate experimentally that SAILs generally outperform NAILs at elevated temperatures, we synthesized three other SAILs, $\left[\mathrm{C}_{4} \mathrm{C}_{1} \mathrm{Im}\right]\left[\mathrm{C}_{8} \mathrm{SO}_{4}\right], \quad\left[\mathrm{C}_{4} \mathrm{C}_{1} \mathrm{Im}\right]\left[\mathrm{C}_{10} \mathrm{SO}_{4}\right]$ and $\left[\mathrm{C}_{4} \mathrm{C}_{1} \mathrm{Im}\right]\left[\mathrm{C}_{12} \mathrm{SO}_{4}\right]$ (Supplementary Fig. 10 and Supplementary Table 6). Their SANS profiles (Fig. 6a) at 70 display clear Bragg peaks at $q=0.24,0.22$ and $0.22^{-1}$, respectively, indicating repeat structures with characteristic dimensions of 26,28 and 28 , respectively. The SANS profiles at 25 and 50 for $\left[\mathrm{C}_{4} \mathrm{C}_{1} \mathrm{Im}\right]\left[\mathrm{C}_{8} \mathrm{SO}_{4}\right]$ and $\left[\mathrm{C}_{4} \mathrm{C}_{1} \operatorname{Im}\right]\left[\mathrm{C}_{10} \mathrm{SO}_{4}\right]$ are similar to those at 70 . The long chain analogue $\left[\mathrm{C}_{4} \mathrm{C}_{1} \mathrm{Im}\right]\left[\mathrm{C}_{12} \mathrm{SO}_{4}\right]$ is solid at low temperatures $\left(25\right.$ and 50 ), resulting a Bragg peak at $q=0.31^{-1}$. Fig. $6 \mathrm{~b}$ depicts the specific capacitances (left axis) of the three SAILs (using CNT supercapacitors), together with the enhancement (right axis) relative to those of $\left[\mathrm{C}_{4} \mathrm{C}_{1} \operatorname{Im}\right]\left[\mathrm{BF}_{4}\right]$. Relative to $\left[\mathrm{C}_{4} \mathrm{C}_{1} \mathrm{Im}\right]\left[\mathrm{BF}_{4}\right]$, and at high temperature (130 ), these SAILs exhibit larger capacitances with a two- to three-fold enhancement, similar to the findings with $\left[\mathrm{C}_{4} \mathrm{C}_{1} \mathrm{Im}\right][\mathrm{AOT}]$ (Supplementary Fig. 6).

The energy storage performance of SAILs depends not only on temperature but also on the operating voltage window. For example, whether $\left[\mathrm{C}_{4} \mathrm{C}_{1} \mathrm{Im}\right][\mathrm{AOT}]$ exhibits larger or smaller differential capacitances than $\left[\mathrm{C}_{4} \mathrm{C}_{1} \mathrm{Im}\right]\left[\mathrm{BF}_{4}\right]$ depends on the degree of electrode polarization (i.e. the applied potential), as shown experimentally (Fig. 4) and also via MD simulations (Fig. 2h). Therefore, when operating over a wide voltage window, a supercapacitor with $\left[\mathrm{C}_{4} \mathrm{C}_{1} \mathrm{Im}\right][\mathrm{AOT}]$ should show larger capacitances than if $\left[\mathrm{C}_{4} \mathrm{C}_{1} \mathrm{Im}\right]\left[\mathrm{BF}_{4}\right]$ is used, whereas when operating over a narrow voltage window, the order is reversed. However, $\left[\mathrm{C}_{4} \mathrm{C}_{1} \mathrm{Im}\right][\mathrm{AOT}]$ is preferred for energy storage applications because in practice it is advantageous to have large capacitances when operating over broad voltage windows since energy density scales as $\int_{0}^{V} C U d U$ or $C V^{2}$, where $C$ is the capacitance, $U$ is the applied potential, and $V$ is the operating voltage window.

The Ragone plot (Supplementary Fig. 14) shows that at low temperatures, the high viscosity of $\left[\mathrm{C}_{4} \mathrm{C}_{1} \mathrm{Im}\right][\mathrm{AOT}]$ results in energy density/power density combinations that are worse than those of $\left[\mathrm{C}_{4} \mathrm{C}_{1} \mathrm{Im}\right]\left[\mathrm{BF}_{4}\right]$. However, at high temperatures where $\left[\mathrm{C}_{4} \mathrm{C}_{1} \operatorname{Im}\right][\mathrm{AOT}]$ is more fluid, it outperforms 
$271\left[\mathrm{C}_{4} \mathrm{C}_{1} \mathrm{Im}\right]\left[\mathrm{BF}_{4}\right]$ in terms of both energy and power density, making $\left[\mathrm{C}_{4} \mathrm{C}_{1} \mathrm{Im}\right][\mathrm{AOT}]$ particularly suitable 272 for important high-temperature applications ${ }^{36}$. Also, mixing $\left[\mathrm{C}_{4} \mathrm{C}_{1} \operatorname{Im}\right][\mathrm{AOT}]$ with $\left[\mathrm{C}_{4} \mathrm{C}_{1} \mathrm{Im}\right]\left[\mathrm{BF} \mathrm{F}_{4}\right]$ led to 273 higher capacitances than those of individual component alone at room temperature (Supplementary Fig. 274 9), suggesting a path to engineer SAIL-based energy devices for low-temperature uses. Due to their 275 larger ion sizes, SAILs might not adsorb so easily into ultranarrow pores with certain porous carbon 276 electrodes $^{37}$; however, SAILs could be used in combination with other nonporous high-surface-area 277 electrodes such as onion-like carbon $^{38}$, carbon nanocage ${ }^{39}$ and carbon fibers ${ }^{40,41}$. Moreover, the 278 electrocapacitive performance of SAILs depends on the specific chemical structure (e.g., the length of 279 the alkyl chains), because these determine the strength of interactions between alkyl chains, as well as 280 between the electrode surfaces and alkyl chains. Therefore, SAIL chemical architecture dictates i) how 281 the density of neutral tails varies with the applied potential, and ii) how effective the self-assembled 282 nonpolar domains are for preventing overscreening. These two factors combined would ultimately 283 determine the shape of the capacitance versus potential profile, which can provide direct information on 284 the performance of SAILs and the desired operation voltages.

In conclusion, this study reveals a fundamentally new interfacial phenomenon where the selfassembled nanostructures in ionic liquids facilitate charge storage at electrified surfaces. This paves the 288 way for building "designer" SAILs, since there are a huge number of possible anion-cation combinations that can be employed to fine-tune the self-assembled nanostructures of SAILs and hence control interfacial electrochemical properties. Additionally, due to exceptional stability and tunable electrochemical performance, rationally engineered SAILs could be used for a wide array of nextgeneration electrochemical devices for improved safety (e.g., avoidance of flammable organic electrolytes in batteries ${ }^{42}$ ), and afford electrochemical modulation in vivo (e.g., drug delivery ${ }^{43}$ ) or for gas-based applications (e.g., $\mathrm{CO}_{2}$ capture ${ }^{44}$, gas sensing ${ }^{45}$, biomimetic multiphase transport ${ }^{46}$ ). More 296 broadly, the self-assembly-based charge storage mechanism discovered here offers a new approach for optimizing interfacial electrochemical behavior of other fluids with ordered nanostructures beyond 297 SAILs (e.g., liquid crystals, block copolymer electrolytes, emulsions), and could have profound impacts 298 on related emerging technologies. 
a
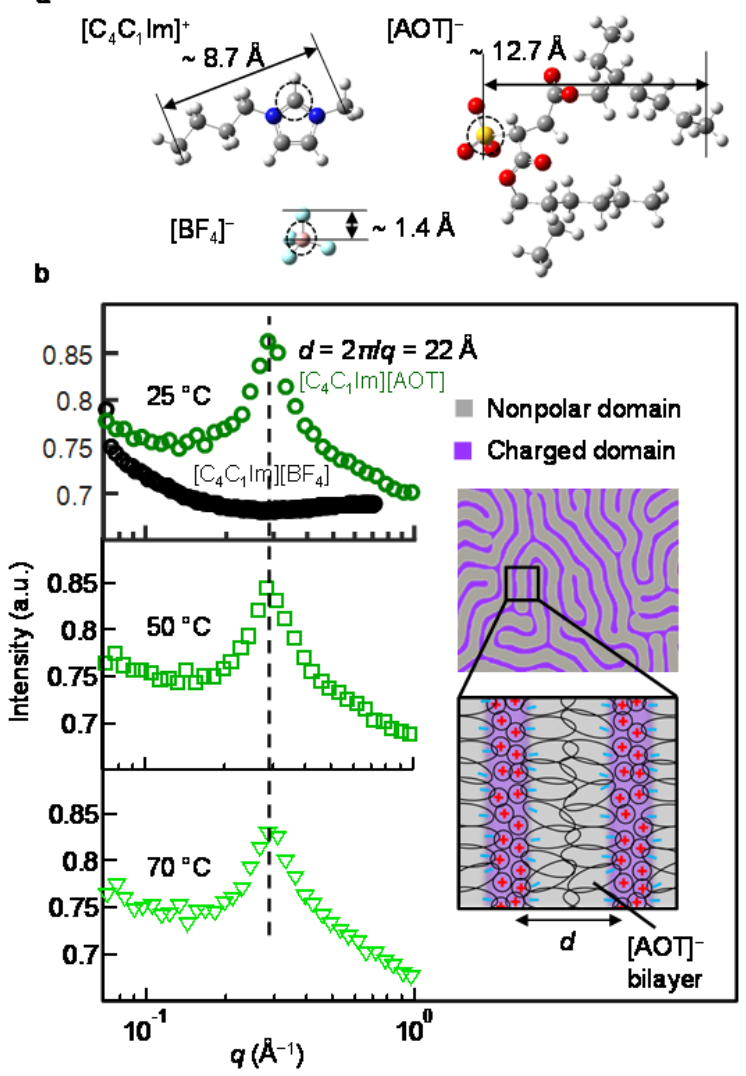

c

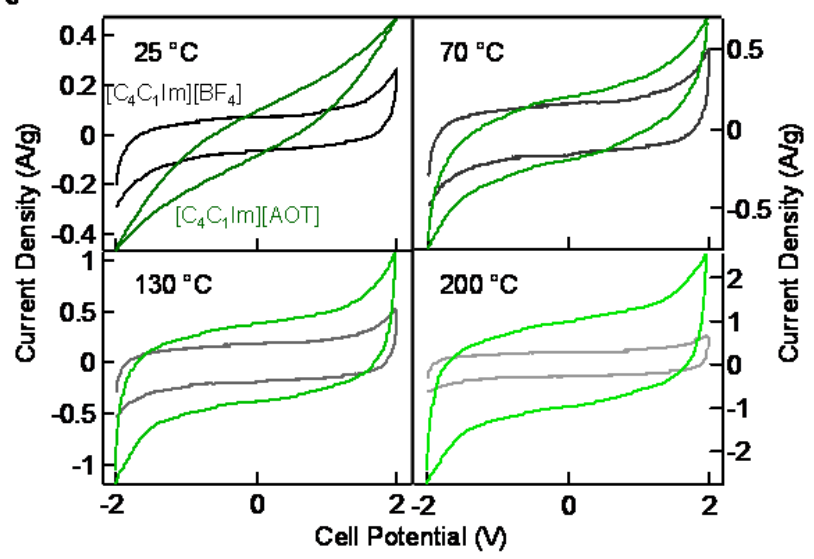

d

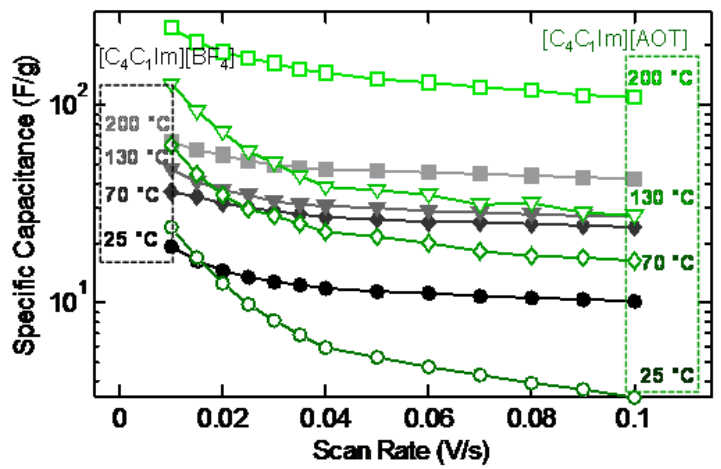

Fig. 1. Bulk-phase structural and electrochemical characterization of $\left[\mathrm{C}_{4} \mathrm{C}_{1} \mathrm{Im}\right][\mathrm{AOT}]$. a, Molecular structures of $\left[\mathrm{C}_{4} \mathrm{C}_{1} \mathrm{Im}\right]^{+},\left[\mathrm{BF}_{4}\right]^{-}$, and $[\mathrm{AOT}]^{-}(\mathrm{H}=$ white, $\mathrm{C}=$ gray, $\mathrm{N}=$ blue, $\mathrm{S}=$ yellow, $\mathrm{O}=$ red, $\mathrm{B}=$ pink, $\mathrm{F}=$ cyan $)$. Typical distances in the molecular ions are indicated. $\mathbf{b}$, SANS profiles of $\left[\mathrm{C}_{4} \mathrm{C}_{1} \mathrm{Im}\right]\left[\mathrm{BF}_{4}\right](25)$ and $\left[\mathrm{C}_{4} \mathrm{C}_{1} \mathrm{Im}\right][\mathrm{AOT}](25,50,70)$. Inset: illustration of self-assembly of $\left[\mathrm{C}_{4} \mathrm{C}_{1} \mathrm{Im}\right][\mathrm{AOT}]$ leading to a repeating nanostructure comprising [AOT] ${ }^{-}$bilayers (red: cation; blue: anion). Simulated SANS profiles (Supplementary Fig. 11) are consistent with the experimental data. c-d, CV profiles (scan rate $=20 \mathrm{mV} / \mathrm{s}$ ) (c) and specific capacitance versus scan rate $(\mathbf{d})$ for $\left[\mathrm{C}_{4} \mathrm{C}_{1} \mathrm{Im}\right]\left[\mathrm{BF}_{4}\right]$ or $\left[\mathrm{C}_{4} \mathrm{C}_{1} \mathrm{Im}\right][\mathrm{AOT}]$ at $25,70,130$ and 200 . 

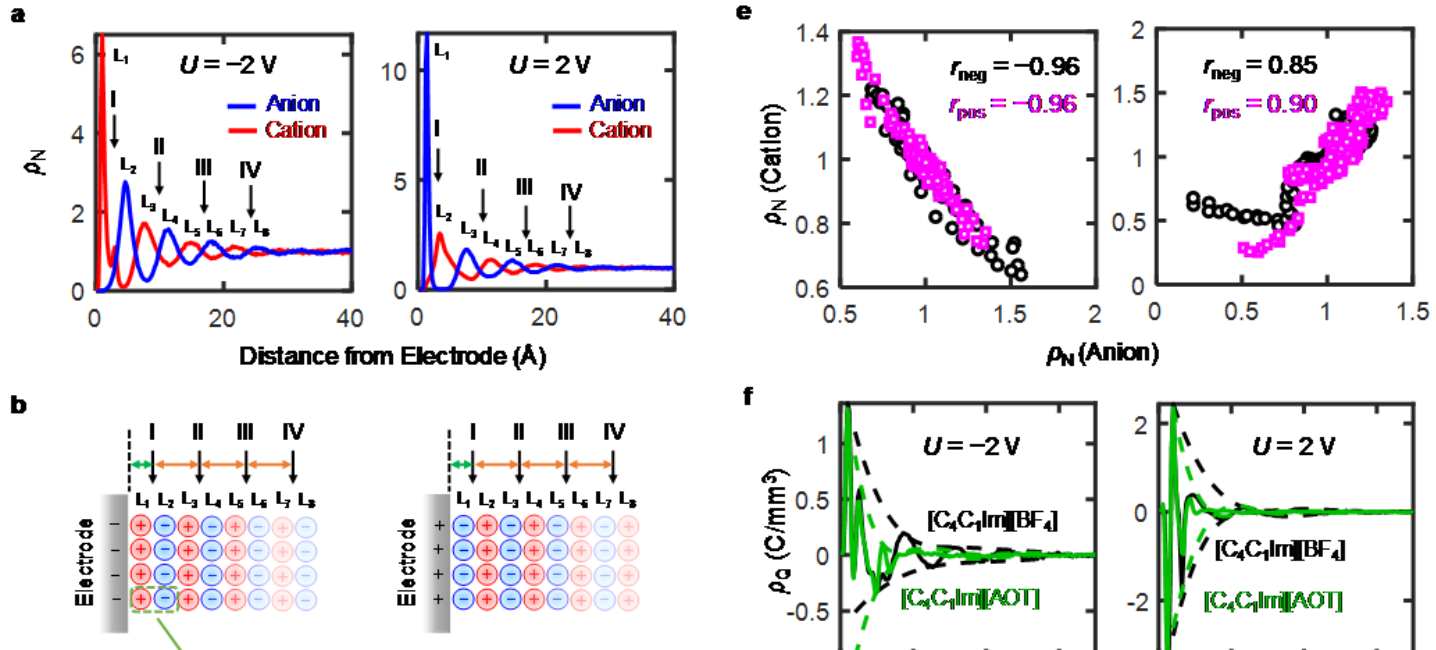

$\mathbf{f}$
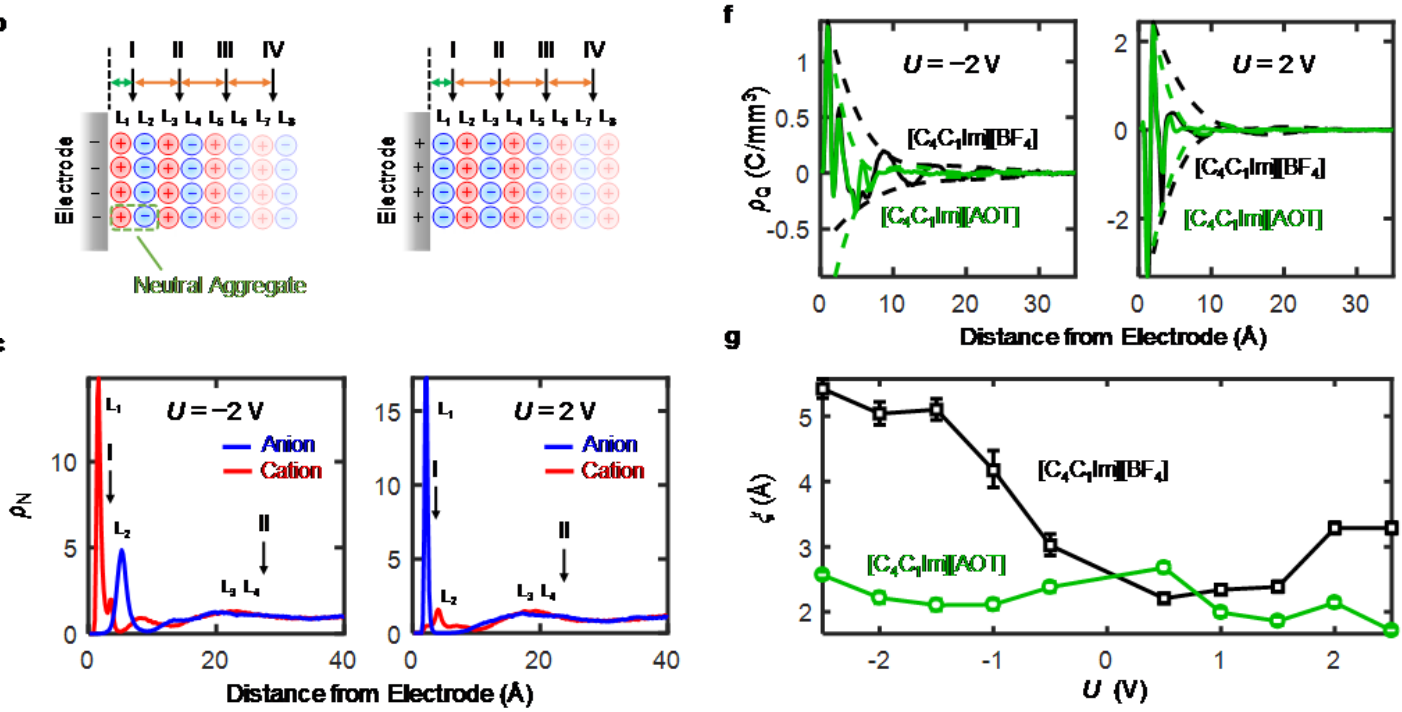

d
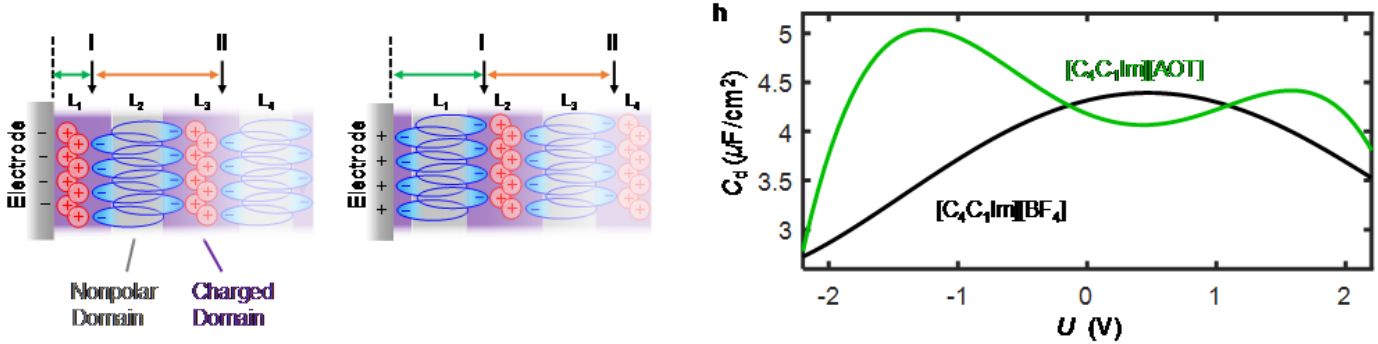

Fig. 2. MD simulations reveal unusual EDL structures of $\left[\mathbf{C}_{4} \mathbf{C}_{1} \mathbf{I m}\right][\mathbf{A O T}]$. a-d, Ion number density $\left(\rho_{\mathrm{N}}\right)$ profile obtained from MD simulations and schematic illustration of hypothesized ion arrangement for $\left[\mathrm{C}_{4} \mathrm{C}_{1} \mathrm{Im}\right]\left[\mathrm{BF}_{4}\right](\mathbf{a}, \mathbf{b})$ and $\left[\mathrm{C}_{4} \mathrm{C}_{1} \mathrm{Im}\right][\mathrm{AOT}](\mathbf{c}, \mathbf{d})$ at negatively (left panel) and positively (right panel) charged interfaces with applied potentials $(U)$ of $\pm 2 \mathrm{~V}$. Black arrows with I, II, III and IV indicate possible positions corresponding to the AFM push-through locations (Fig. 3). e, Correlations between the cationic and anionic $\rho_{\mathrm{N}}$ obtained at positively (magenta, $U=2 \mathrm{~V}$ ) and negatively (black, $U=$ $-2 \mathrm{~V}$ ) charged interfaces for $\left[\mathrm{C}_{4} \mathrm{C}_{1} \mathrm{Im}\right]\left[\mathrm{BF}_{4}\right]$ (left panel) and $\left[\mathrm{C}_{4} \mathrm{C}_{1} \mathrm{Im}\right][\mathrm{AOT}]$ (right panel) for the distance range of 10 to 40 away from the interface. $r_{\text {neg }}$ and $r_{\text {pos }}$ are the Pearson correlation coefficients for negatively and positively charged interfaces, respectively. f, Net charge density $\left(\rho_{\mathrm{Q}}\right)$ profiles (solid line) and corresponding envelope functions (dashed line) of $\left[\mathrm{C}_{4} \mathrm{C}_{1} \mathrm{Im}\right]\left[\mathrm{BF}_{4}\right]$ and $\left[\mathrm{C}_{4} \mathrm{C}_{1} \mathrm{Im}\right][\mathrm{AOT}]$ at negatively (left panel, $U=-2 \mathrm{~V}$ ) and positively (right panel, $U=2 \mathrm{~V}$ ) charged interfaces. g-h, Decay length $(\xi)$ of the surface-induced ion layering $(\mathbf{g})$ and differential capacitance $\left(C_{\mathrm{d}}\right)(\mathbf{f})$ as a function of $U$ for $\left[\mathrm{C}_{4} \mathrm{C}_{1} \operatorname{Im}\right]\left[\mathrm{BF}_{4}\right]$ and $\left[\mathrm{C}_{4} \mathrm{C}_{1} \mathrm{Im}\right][\mathrm{AOT}]$. 
a

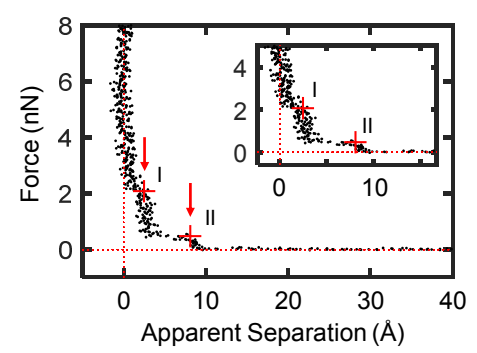

d

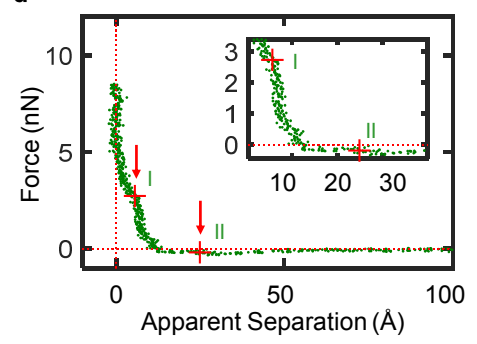

b

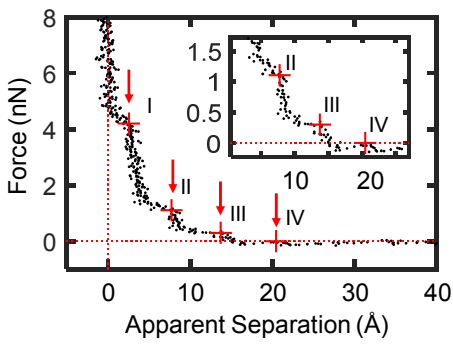

e

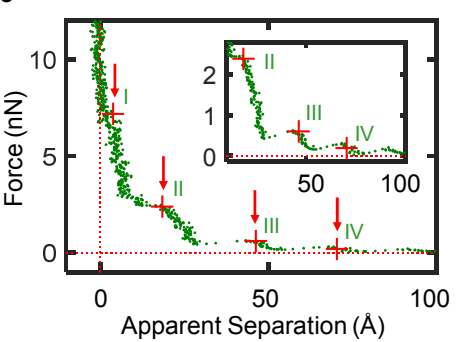

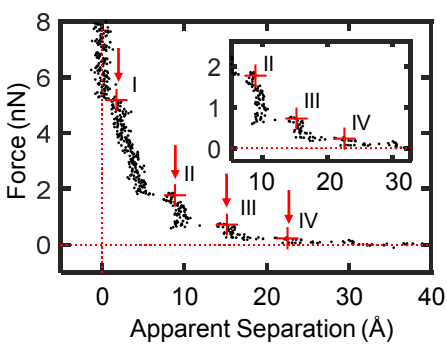

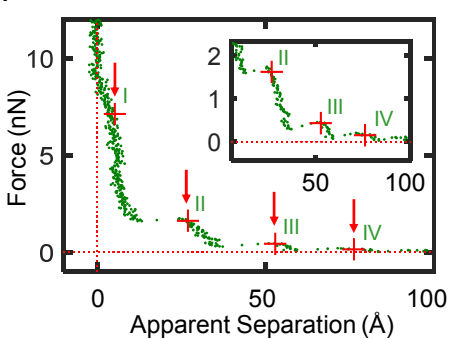

Fig. 3. Elucidation of interfacial molecular layering through AFM force measurements. a-c, Force versus apparent separation profiles obtained with a silica colloid probe approaching a graphite electrode surface immersed in $\left[\mathrm{C}_{4} \mathrm{C}_{1} \mathrm{Im}\right]\left[\mathrm{BF}_{4}\right]$ at OCP (a), OCP $-1 \mathrm{~V}(\mathbf{b})$, and OCP $+1 \mathrm{~V}$ (c). Inset: zoom-in of the lower force regime. Red cross with I, II, III or IV indicates the location of each discrete step and the "rupture force" magnitude. d-f, same as a-c but for the case of $\left[\mathrm{C}_{4} \mathrm{C}_{1} \mathrm{Im}\right][\mathrm{AOT}]$.

a
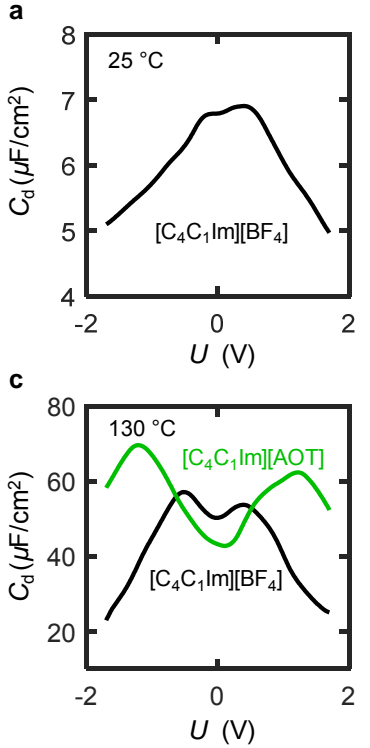
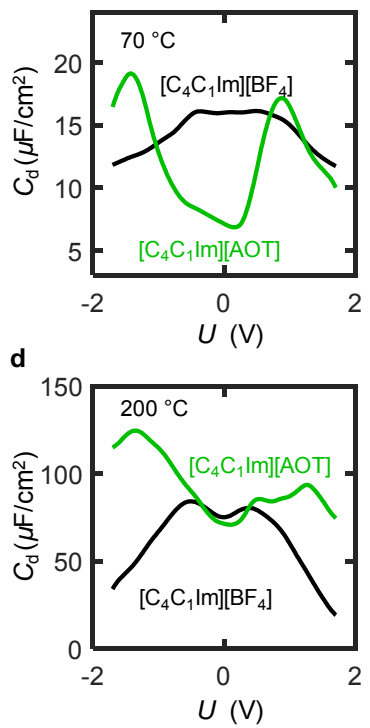

Fig. 4. EDL properties probed by impedance measurements. Experimentally determined differential capacitances as a function of the applied potential $(U$, versus $\mathrm{OCP})$ for $\left[\mathrm{C}_{4} \mathrm{C}_{1} \mathrm{Im}\right]\left[\mathrm{BF}_{4}\right]$ and $\left[\mathrm{C}_{4} \mathrm{C}_{1} \mathrm{Im}\right][\mathrm{AOT}]$ at $25 \quad$ (a), 70 (b), 130 (c), and 200 (d) on a glassy carbon electrode. 
a
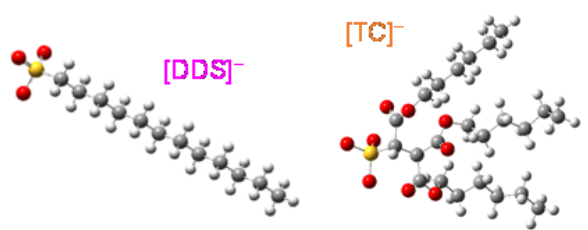

b
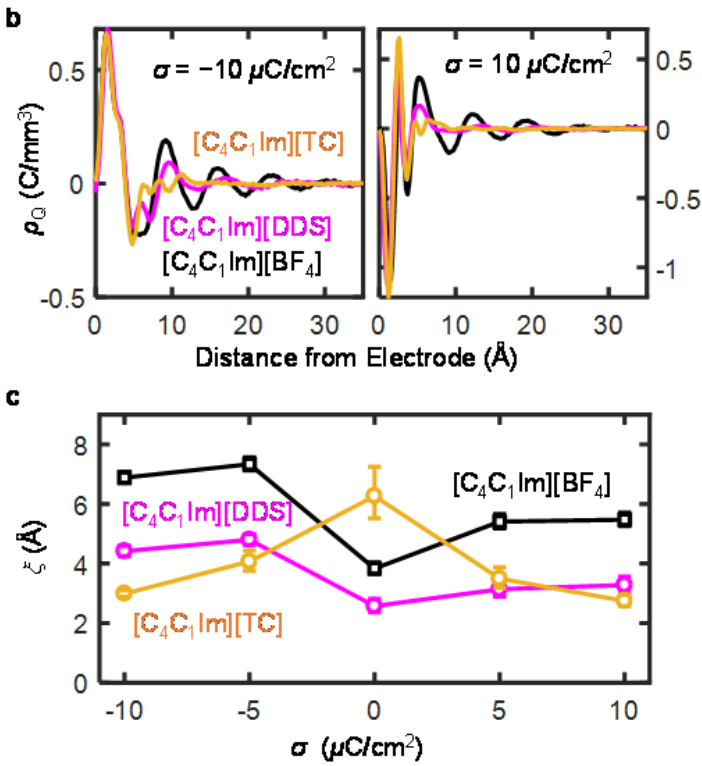

d

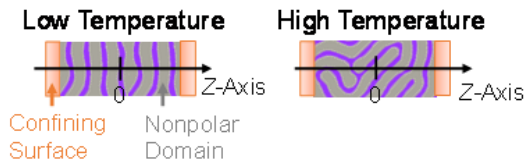

e
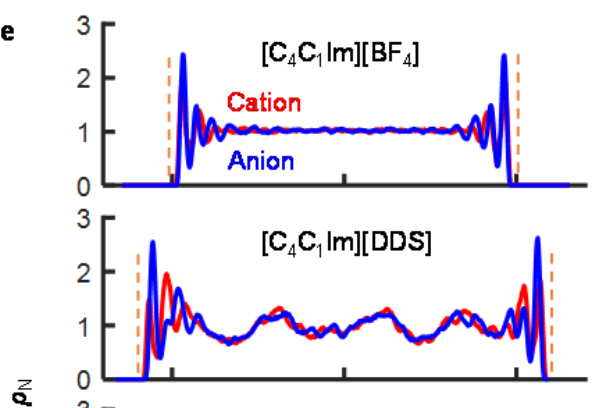

z

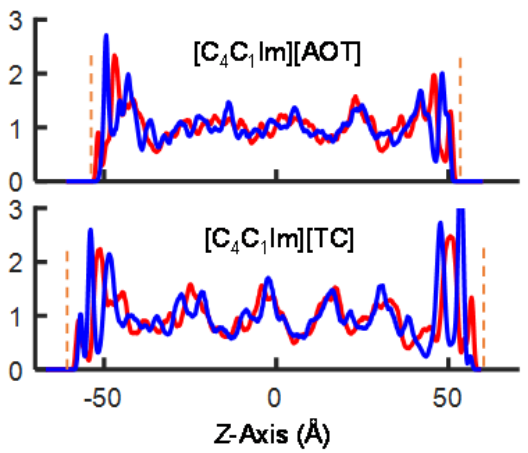

Fig. 5. MD simulations of other SAILs. a, Molecular structures of [DDS $]^{-}$and $\left[\mathrm{TC}^{-}(\mathrm{H}=\right.$ white, $\mathrm{C}=\mathrm{gray}, \mathrm{S}=\mathrm{yellow}, \mathrm{O}=$ red). b, Net charge density $\left(\rho_{\mathrm{Q}}\right)$ profiles of $\left[\mathrm{C}_{4} \mathrm{C}_{1} \mathrm{Im}\right][\mathrm{DDS}],\left[\mathrm{C}_{4} \mathrm{C}_{1} \mathrm{Im}\right][\mathrm{TC}]$ and $\left[\mathrm{C}_{4} \mathrm{C}_{1} \mathrm{Im}\right]\left[\mathrm{BF}_{4}\right]$ at negatively (left panel) and positively (right panel) charged interfaces. c, Decay length $(\xi)$ versus $\sigma$ for $\left[\mathrm{C}_{4} \mathrm{C}_{1} \operatorname{Im}\right][\mathrm{DDS}],\left[\mathrm{C}_{4} \mathrm{C}_{1} \mathrm{Im}\right][\mathrm{TC}]$ and $\left[\mathrm{C}_{4} \mathrm{C}_{1} \mathrm{Im}\right]\left[\mathrm{BF}_{4}\right]$. d, Schematic illustration of the possible orientations of nonpolar domains in SAILs at low (left) and high (right) temperatures. e, Ion number density $\left(\rho_{\mathrm{N}}\right)$ profiles of $\left[\mathrm{C}_{4} \mathrm{C}_{1} \mathrm{Im}\right]\left[\mathrm{BF}_{4}\right],\left[\mathrm{C}_{4} \mathrm{C}_{1} \operatorname{Im}\right][\mathrm{DDS}],\left[\mathrm{C}_{4} \mathrm{C}_{1} \mathrm{Im}\right][\mathrm{AOT}]$ and $\left[\mathrm{C}_{4} \mathrm{C}_{1} \mathrm{Im}\right][\mathrm{TC}]$ at 100 with zero charge on the confining surface. Dashed line: position of the IL/solid interface. 


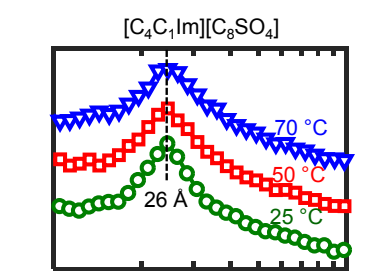

$\left[\mathrm{C}_{4} \mathrm{C}_{1} \mathrm{Im}\right]\left[\mathrm{C}_{10} \mathrm{SO}_{4}\right]$

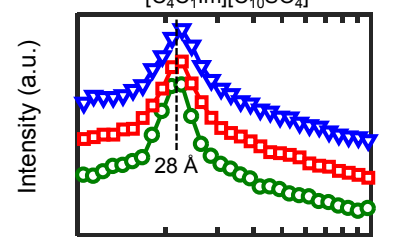

$\left[\mathrm{C}_{4} \mathrm{C}_{1} \operatorname{Im}\right]\left[\mathrm{C}_{12} \mathrm{SO}_{4}\right]$

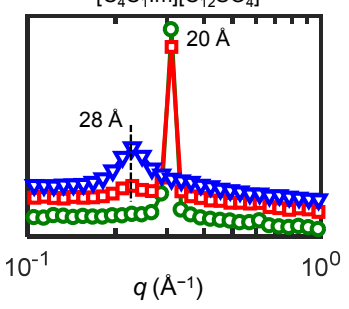

b
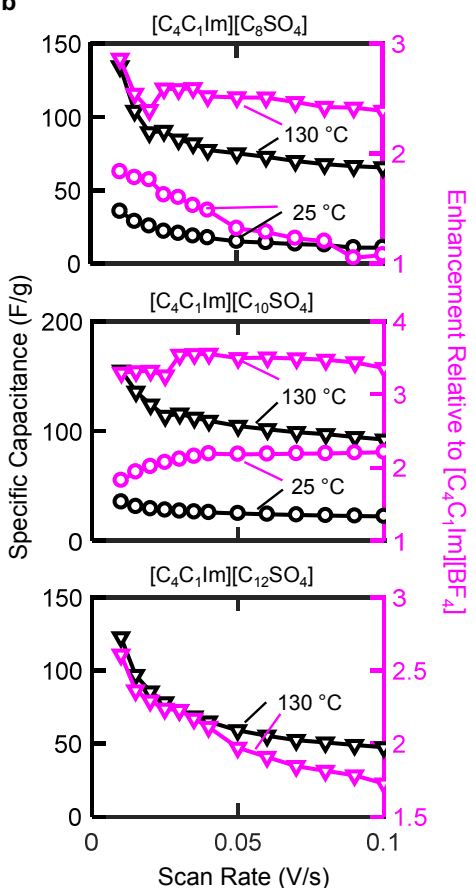

Fig. 6. Electrocapacitive performance of other SAILs. a, SANS profiles of $\left[\mathrm{C}_{4} \mathrm{C}_{1} \mathrm{Im}\right]\left[\mathrm{C}_{8} \mathrm{SO}_{4}\right],\left[\mathrm{C}_{4} \mathrm{C}_{1} \mathrm{Im}\right]\left[\mathrm{C}_{10} \mathrm{SO}_{4}\right]$ and $\left[\mathrm{C}_{4} \mathrm{C}_{1} \mathrm{Im}\right]\left[\mathrm{C}_{12} \mathrm{SO}_{4}\right]$ at 25,50 and 70 . b, Specific capacitance (left axis) versus scan rate for $\left[\mathrm{C}_{4} \mathrm{C}_{1} \mathrm{Im}\right]\left[\mathrm{C}_{8} \mathrm{SO}_{4}\right](25$ and 130 ), $\left[\mathrm{C}_{4} \mathrm{C}_{1} \mathrm{Im}\right]\left[\mathrm{C}_{10} \mathrm{SO}_{4}\right]\left(25\right.$ and $130 \quad$ ) or $\left[\mathrm{C}_{4} \mathrm{C}_{1} \mathrm{Im}\right]\left[\mathrm{C}_{12} \mathrm{SO}_{4}\right](130 \quad)$, together with the enhancement factor (right axis) compared to the performance of $\left[\mathrm{C}_{4} \mathrm{C}_{1} \mathrm{Im}\right]\left[\mathrm{BF}_{4}\right]$. 


\section{References}

3581 MacFarlane, D. R., Forsyth, M., Howlett, P. C., Kar, M., Passerini, S., Pringle, J. M., Ohno, H., Watanabe, M., Yan, F., Zheng, W. J., Zhang, S. G. \& Zhang, J. Ionic liquids and their solid-state analogues as materials for energy generation and storage. Nature Reviews Materials 1, (2016).

2 Salanne, M., Rotenberg, B., Naoi, K., Kaneko, K., Taberna, P. L., Grey, C. P., Dunn, B. \& Simon, P. Efficient storage mechanisms for building better supercapacitors. Nature Energy 1, (2016).

3 Li, Y., Wang, X. G., Dong, S. M., Chen, X. \& Cui, G. L. Recent Advances in Non-Aqueous Electrolyte for Rechargeable Li-O-2 Batteries. Advanced Energy Materials 6, (2016).

4 Armand, M., Endres, F., MacFarlane, D. R., Ohno, H. \& Scrosati, B. Ionic-liquid materials for the electrochemical challenges of the future. Nature Materials 8, 621-629, (2009).

5 Che, H. Y., Chen, S. L., Xie, Y. Y., Wang, H., Amine, K., Liao, X. Z. \& Ma, Z. F. Electrolyte design strategies and research progress for room-temperature sodium-ion batteries. Energy \& Environmental Science 10, 1075-1101, (2017).

6 Fedorov, M. V. \& Kornyshev, A. A. Ionic Liquids at Electrified Interfaces. Chemical Reviews 114, 29783036, (2014).

7 Bazant, M. Z., Storey, B. D. \& Kornyshev, A. A. Double Layer in Ionic Liquids: Overscreening versus Crowding. Physical Review Letters 106, (2011).

8 Gebbie, M. A., Dobbs, H. A., Valtiner, M. \& Israelachvili, J. N. Long-range electrostatic screening in ionic liquids. Proceedings of the National Academy of Sciences of the United States of America 112, 7432-7437, (2015).

9 Zhou, H., Rouha, M., Feng, G., Lee, S. S., Docherty, H., Fenter, P., Cummings, P. T., Fulvio, P. F., Dai, S., McDonough, J., Presser, V. \& Gogotsi, Y. Nanoscale Perturbations of Room Temperature Ionic Liquid Structure at Charged and Uncharged Interfaces. Acs Nano 6, 9818-9827, (2012).

10 Gebbie, M. A., Valtiner, M., Banquy, X., Fox, E. T., Henderson, W. A. \& Israelachvili, J. N. Ionic liquids behave as dilute electrolyte solutions. Proceedings of the National Academy of Sciences of the United States of America 110, 9674-9679, (2013).

11 Mezger, M., Schroder, H., Reichert, H., Schramm, S., Okasinski, J. S., Schoder, S., Honkimaki, V., Deutsch, M., Ocko, B. M., Ralston, J., Rohwerder, M., Stratmann, M. \& Dosch, H. Molecular layering of fluorinated ionic liquids at a charged sapphire (0001) surface. Science 322, 424-428, (2008).

12 Crowhurst, L., Lancaster, N. L., Arlandis, J. M. P. \& Welton, T. Manipulating solute nucleophilicity with room temperature ionic liquids. Journal of the American Chemical Society 126, 11549-11555, (2004).

13 Zhang, S. G., Zhang, J. H., Zhang, Y. \& Deng, Y. Q. Nanoconfined Ionic Liquids. Chemical Reviews 117, 6755-6833, (2017).

14 Elbourne, A., Voitchovsky, K., Warr, G. G. \& Atkin, R. Ion structure controls ionic liquid near-surface and interfacial nanostructure. Chemical Science 6, 527-536, (2015).

15 Lopes, J. N. A. C. \& Padua, A. A. H. Nanostructural organization in ionic liquids. Journal of Physical Chemistry B 110, 3330-3335, (2006).

16 Padua, A. A. H., Gomes, M. F. \& Lopes, J. N. A. C. Molecular solutes in ionic liquids: A structural, perspective. Accounts of Chemical Research 40, 1087-1096, (2007).

17 Dong, K., Liu, X. M., Dong, H. F., Zhang, X. P. \& Zhang, S. J. Multiscale Studies on Ionic Liquids. Chemical Reviews 117, 6636-6695, (2017).

18 McDonald, S., Murphy, T., Imberti, S., Warr, G. G. \& Atkin, R. Amphiphilically Nanostructured Deep Eutectic Solvents. The Journal of Physical Chemistry Letters 9, 3922-3927, (2018).

19 Brown, P., Butts, C. P., Eastoe, J., Fermin, D., Grillo, I., Lee, H.-C., Parker, D., Plana, D. \& Richardson, R. M. Anionic Surfactant Ionic Liquids with 1-Butyl-3-methyl-imidazolium Cations: Characterization and Application. Langmuir 28, 2502-2509, (2012).

20 Kim, Y. K., Wang, X. G., Mondkar, P., Bukusoglu, E. \& Abbott, N. L. Self-reporting and self-regulating liquid crystals. Nature 557, 539-+, (2018). 
Futamura, R., Iiyama, T., Takasaki, Y., Gogotsi, Y., Biggs, M. J., Salanne, M., Segalini, J., Simon, P. \& Kaneko, K. Partial breaking of the Coulombic ordering of ionic liquids confined in carbon nanopores. Nature Materials 16, 1225-+, (2017).

22 Mefford, J. T., Hardin, W. G., Dai, S., Johnston, K. P. \& Stevenson, K. J. Anion charge storage through oxygen intercalation in LaMnO3 perovskite pseudocapacitor electrodes. Nature Materials 13, 726-732, (2014).

23 Xia, Y., Mathis, T. S., Zhao, M. Q., Anasori, B., Dang, A., Zhou, Z. H., Cho, H., Gogotsi, Y. \& Yang, S. Thickness - independent capacitance of vertically aligned liquid-crystalline MXenes. Nature 557, 409-+, (2018).

24 Zhong, C., Deng, Y. D., Hu, W. B., Qiao, J. L., Zhang, L. \& Zhang, J. J. A review of electrolyte materials and compositions for electrochemical supercapacitors. Chemical Society Reviews 44, 7484-7539, (2015).

25 Smith, A. M., Lovelock, K. R. J., Gosvami, N. N., Licence, P., Dolan, A., Welton, T. \& Perkin, S. Monolayer to Bilayer Structural Transition in Confined Pyrrolidinium-Based Ionic Liquids. The Journal of Physical Chemistry Letters 4, 378-382, (2013).

26 Kornyshev, A. A. Double-Layer in Ionic Liquids: Paradigm Change? The Journal of Physical Chemistry B 111, 5545-5557, (2007).

27 Pak, A. J., Paekw, E. \& Hwang, G. S. Relative contributions of quantum and double layer capacitance to the supercapacitor performance of carbon nanotubes in an ionic liquid. Physical Chemistry Chemical Physics 15, 19741-19747, (2013).

28 Merlet, C., Rotenberg, B., Madden, P. A., Taberna, P.-L., Simon, P., Gogotsi, Y. \& Salanne, M. On the molecular origin of supercapacitance in nanoporous carbon electrodes. Nature Materials 11, 306, (2012).

29 Fedorov, M. V., Georgi, N. \& Kornyshev, A. A. Double layer in ionic liquids: The nature of the camel shape of capacitance. Electrochemistry Communications 12, 296-299, (2010).

30 Georgi, N., Kornyshev, A. A. \& Fedorov, M. V. The anatomy of the double layer and capacitance in ionic liquids with anisotropic ions: Electrostriction vs. lattice saturation. Journal of Electroanalytical Chemistry 649, 261-267, (2010).

31 Perkin, S., Crowhurst, L., Niedermeyer, H., Welton, T., Smith, A. M. \& Gosvami, N. N. Self-assembly in the electrical double layer of ionic liquids. Chemical Communications 47, 6572-6574, (2011).

32 Hayes, R., Warr, G. G. \& Atkin, R. Structure and Nanostructure in Ionic Liquids. Chemical Reviews 115, 6357-6426, (2015).

33 Espinosa-Marzal, R. M., Han, M., Arcifa, A., Spencer, N. D. \& Rossi, A. in Encyclopedia of Interfacial Chemistry (ed Klaus Wandelt) 172-194 (Elsevier, 2018).

34 Werzer, O., Cranston, E. D., Warr, G. G., Atkin, R. \& Rutland, M. W. Ionic liquid nanotribology: micasilica interactions in ethylammonium nitrate. Physical Chemistry Chemical Physics 14, 5147-5152, (2012).

35 Voïtchovsky, K. Anharmonicity, solvation forces, and resolution in atomic force microscopy at the solidliquid interface. Physical Review E 88, 022407, (2013).

36 Lin, X., Salari, M., Arava, L. M. R., Ajayan, P. M. \& Grinstaff, M. W. High temperature electrical energy storage: advances, challenges, and frontiers. Chemical Society Reviews 45, 5848-5887, (2016).

37 Simon, P. \& Gogotsi, Y. Capacitive Energy Storage in Nanostructured Carbon-Electrolyte Systems. Accounts of Chemical Research 46, 1094-1103, (2013).

38 Pech, D., Brunet, M., Durou, H., Huang, P., Mochalin, V., Gogotsi, Y., Taberna, P.-L. \& Simon, P. Ultrahigh-power micrometre-sized supercapacitors based on onion-like carbon. Nature Nanotechnology $\mathbf{5}$, 651, (2010).

39 Xie, K., Qin, X., Wang, X., Wang, Y., Tao, H., Wu, Q., Yang, L. \& Hu, Z. Carbon Nanocages as Supercapacitor Electrode Materials. Advanced Materials 24, 347-352, (2012).

40 Mao, X., Yang, X., Wu, J., Tian, W., Rutledge, G. C. \& Hatton, T. A. Microwave-Assisted Oxidation of Electrospun Turbostratic Carbon Nanofibers for Tailoring Energy Storage Capabilities. Chemistry of Materials 27, 4574-4585, (2015).

41 Mao, X. W., Simeon, F., Rutledge, G. C. \& Hatton, T. A. Electrospun Carbon Nanofiber Webs with Controlled Density of States for Sensor Applications. Advanced Materials 25, 1309-1314, (2013). 
$45642 \quad$ Li, J. C., Ma, C., Chi, M. F., Liang, C. D. \& Dudney, N. J. Solid Electrolyte: the Key for High-Voltage Lithium Batteries. Advanced Energy Materials 5, (2015).

43 Alshammary, B., Walsh, F. C., Herrasti, P. \& Ponce de Leon, C. Electrodeposited conductive polymers for controlled drug release: polypyrrole. Journal of Solid State Electrochemistry, 1-21, (2015).

44 Stern, M. C., Simeon, F., Herzog, H. \& Hatton, T. A. Post-combustion carbon dioxide capture using electrochemically mediated amine regeneration. Energy \& Environmental Science 6, 2505-2517, (2013).

45 Wang, L. D., Drahushuk, L. W., Cantley, L., Koenig, S. P., Liu, X. H., Pellegrino, J., Strano, M. S. \& Bunch, J. S. Molecular valves for controlling gas phase transport made from discrete angstrom-sized pores in graphene. Nature Nanotechnology 10, 785-+, (2015).

46 Hou, X., Hu, Y. H., Grinthal, A., Khan, M. \& Aizenberg, J. Liquid-based gating mechanism with tunable multiphase selectivity and antifouling behaviour. Nature 519, 70-73, (2015).

\section{Acknowledgments}

This work was supported by an MIT Energy Initiative seed grant. X.M. acknowledges financial support from an MIT Skoltech fellowship. C. C. acknowledges financial support from the Czech Science Foundation (GACR No.19-04150Y). C. C. and A. P. thank Dr. Alain Dequidt of Université Clermont Auvergne for the use of the computer program to calculate structure factors. The UK research council STFC is thanked for the provision of beam time at Institut Laue Langevin, Grenoble, France.

\section{Author contributions}

X.M. and P.B. conceived the initial idea. X.M. designed and led the research, carried out electrochemical experiments, and analyzed experimental and simulation data, under the supervision of T.A.H. P.B. synthesized SAILs and contributed to electrochemical experiments, under the supervision of T.A.H. C.C. carried out MD simulations under the supervision of A.A.H.P. and M.F.C.G. G.H. performed SANS experiments under the supervision of J.E. and I.G. H.L. performed AFM force measurements under the supervision of R.A. Y.R. contributed to synthesis of SAILs and x-ray reflectivity measurements. D.C. performed x-ray reflectivity measurements. X.M. wrote the manuscript. All authors revised the manuscript.

\section{Competing interests}

X.M., P.B., M.F.C.G., and T.A.H. have filed a patent application based on this work. Title: HIGHTEMPERATURE SUPERCAPACITORS CONTAINING SURFACE ACTIVE IONIC LIQUIDS. Filed 
488 with the U.S. Patent and Trademark Office (U.S. Patent Application No.: 16/323,468) on February 5, 489 2019, and published on June 20, 2019 with Publication No. US-2019-0189364-A1. 


\section{Methods}

491 Synthesis of SAILs. 1-Butyl-3-methyl-imidazolium chloride $\left(\left[\mathrm{C}_{4} \mathrm{C}_{1} \mathrm{Im}\right][\mathrm{Cl}], \geq 99 \%\right)$ was purchased from Sigma-Aldrich and used as received. Aerosol-OT (AOT, sodium 1,4-bis(2-ethylhexoxy)-1,4dioxobutane-2-sulfonate) was purchased from Sigma-Aldrich and purified by Soxhlet extraction using dry acetone and subjected to repeated centrifugation. Ethyl acetate ( $\geq 99.5 \%)$ was purchased from Sigma-Aldrich and used without further purification. The ionic liquid 1-butyl-3-methylimidazolium 1,4bis(2-ethylhexoxy)-1,4-dioxobutane-2-sulfonate, $\left[\mathrm{C}_{4} \mathrm{C}_{1} \mathrm{Im}\right][\mathrm{AOT}]$ was synthesized via an ion-exchange technique ${ }^{19}$ using a strong ion exchange resin (Amberlite IR $120 \mathrm{H}^{+}$form) as follows: surfactant (sodium salt, $50 \mathrm{mmol})$ dissolved in $100 \mathrm{ml} \mathrm{EtOH} / \mathrm{H}_{2} \mathrm{O}(1: 1 \mathrm{v} / \mathrm{v})$ and passed through a column $(20 \mathrm{~cm} \mathrm{x} 2$ $\mathrm{cm}^{2}$ ) of the ion exchange resin. For synthesis of $\left[\mathrm{C}_{4} \mathrm{C}_{1} \mathrm{Im}\right]\left[\mathrm{C}_{8} \mathrm{SO}_{4}\right], \quad\left[\mathrm{C}_{4} \mathrm{C}_{1} \mathrm{Im}\right]\left[\mathrm{C}_{10} \mathrm{SO}_{4}\right]$ and $\left[\mathrm{C}_{4} \mathrm{C}_{1} \mathrm{Im}\right]\left[\mathrm{C}_{12} \mathrm{SO}_{4}\right]$, Sodium octyl sulfate $\left(>99.0 \%\right.$, [Na] $\left.\left[\mathrm{C}_{8} \mathrm{SO}_{4}\right]\right)$, sodium decyl sulfate $(>99.0 \%$, $\left.[\mathrm{Na}]\left[\mathrm{C}_{10} \mathrm{SO}_{4}\right]\right)$, and sodium dodecyl sulfate $\left(>99.0 \%\right.$, [Na][C $\left.\left.{ }_{12} \mathrm{SO}_{4}\right]\right)$ were purchased form Sigma Aldrich and used without further purification. These surfactants were also converted into ionic liquids via an ion-exchange technique as for the $\left[\mathrm{C}_{4} \mathrm{C}_{1} \mathrm{Im}\right][\mathrm{AOT}]$. Details on the synthesis and characterization of SAILs are presented in Supplementary Note 1.

Small-angle neutron scattering. Scattering was measured on the D22 diffractometer at ILL, Grenoble, France. A neutron wavelength of $\lambda=10 \AA$ was employed at two different detector distances, giving $0.0024<Q<0.37 \AA^{-1}$. Data normalization using accepted procedures gave the absolute cross section $I(Q)\left(\mathrm{cm}^{-1}\right)$ as a function of momentum transfer $Q\left(\AA^{-1}\right)$. Samples were placed in Hellma fused silica cuvettes: path length $2 \mathrm{~mm}$. Additional data analysis procedures are discussed in Supplementary Note 2 .

Electrochemical experiments. All electrochemical measurements of the supercapacitor devices were carried out with a VersaSTAT4 potentiostat (Princeton Applied Research) in a two-electrode electrochemical cell thermostatted at the temperature of interest $\left( \pm 1^{\circ} \mathrm{C}\right)$. For the construction of the MWCNT supercapacitor devices ${ }^{40}$, two pieces of MWCNT-deposited Toray carbon paper (active area $=$ $2 \mathrm{~cm}^{2}$, mass loading $=2.67 \mathrm{mg} / \mathrm{cm}^{2}$ ) were assembled with a VWR filter paper sandwiched between them as the separator. The entire assembly was then sandwiched between two microscope glass slides, and dipped in the ionic liquid of interest. The two Toray carbon papers were attached to conductive copper tapes, which were connected to the potentiostat via alligator clips. The SWCNT and AC supercapacitor devices were assembled similarly as in the case of MWCNTs. Electrochemical impedance measurements were performed in a three-electrode system that consists of i) a flat-surface working 
electrode (either glassy carbon electrode with a diameter of $3.0 \mathrm{~mm}$, or Au electrode with $99.95 \%$ purity and a diameter of $3.0 \mathrm{~mm}$ ), ii) a $\mathrm{Ag} / \mathrm{Ag}^{+}$reference electrode made of a silver wire, $10 \mathrm{mM} \mathrm{AgBF}$, the respective ionic liquid inside a glass tube with a porous CoralPor ${ }^{\mathrm{TM}}$ tip, and iii) a platinum gauze auxiliary electrode (90/10 platinum/iridium alloy, $50.0 \mathrm{~mm}$ height, $38.0 \mathrm{~mm}$ diameter). The heterogeneous electron transfer kinetics on the selected electrode were measured by sampled current voltammetry $(\mathrm{SCV})^{47}$ using an electrolyte solution consisting of $1 \mathrm{mM} \mathrm{Ru}\left(\mathrm{NH}_{3}\right)_{6}{ }^{3+2+}$ and $1.0 \mathrm{M} \mathrm{KCl}$. Details of electrochemical characterizations are presented in Supplementary Note 3.

Molecular dynamics simulation. The $\left[\mathrm{C}_{4} \mathrm{C}_{1} \mathrm{im}\right]^{+}$cation ${ }^{48,49}$ and the $\left[\mathrm{BF}_{4}\right]^{-}$anion were represented by the CL\&P all-atom nonpolarizable force field ${ }^{50}$. For the $[\mathrm{AOT}]^{-}$, $[\mathrm{DDS}]^{-}$, and $[\mathrm{TC}]^{-}$anions, the force field parameters were assembled from existing values of similar molecules containing sulphonate, ether, and alkyl chain groups from OPLS-AA ${ }^{51,52}$ and are listed in Supplementary Table 1-4. The atom types are illustrated in Supplementary Fig. 1. The graphite layers were modeled using the parameterization of Girifalco et al. ${ }^{53}$ Molecular dynamic simulations were performed using the LAMMPS $^{54}$ software package with the Verlet integrator ${ }^{55}$. Short-range forces (Lennard-Jones) were cut-off at $12 \AA$ of interatomic separation and long-range electrostatic forces calculated with the particle-particle particlemesh (PPPM) $)^{56}$ method. The SHAKE algorithm ${ }^{57}$ was employed to keep length of the bonds terminating in hydrogen atoms constant, enabling to use the time step of $1 \mathrm{fs}$ for the simulations with constant electrode charge density. Alternative simulations, during which the electrodes are kept at a constant electrostatic potential difference, were run using the constant potential method (CPM) developed by Siepman et al. ${ }^{58}$ and Reed et al. ${ }^{59}$ and implemented in LAMMPS by Wang et al. ${ }^{60}$ Details on the MD simulations are presented in Supplementary Note 4.1.

Atomic force microscopy. Force-distance profiles were performed using a Veeco NanoScope IV AFM. Three sharp silicon cantilevers (spring constant $0.3 \pm 0.1 \mathrm{~N} / \mathrm{m}$ ) from the same batch (model NSC36, Mikromasch, Tallinn, Estonia) were used over the course of the investigation. The cantilevers were cleaned prior to use by careful rinsing in Milli-Q water and ethanol, drying under nitrogen and irradiation with ultraviolet light for 20 min. An AFM electrochemistry fluid cell (MMTMEC, Bruker) was used to hold ionic liquids on an HOPG surface during the measurements. HOPG was used as both the working electrode and the solid substrate for AFM measurements. Pt wires of $0.25 \mathrm{~mm}$ were used as both the counter and "quasi" reference electrodes. More details on the AFM measurements can be found in Supplementary Note 5. 


\section{Data availability}

552 The data that support the findings of this study are available from the corresponding authors upon 553 reasonable request.

\section{References}

19 Brown, P., Butts, C. P., Eastoe, J., Fermin, D., Grillo, I., Lee, H.-C., Parker, D., Plana, D. \& Richardson, R. M. Anionic Surfactant Ionic Liquids with 1-Butyl-3-methyl-imidazolium Cations: Characterization and Application. Langmuir 28, 2502-2509, (2012).

40 Mao, X., Yang, X., Wu, J., Tian, W., Rutledge, G. C. \& Hatton, T. A. Microwave-Assisted Oxidation of Electrospun Turbostratic Carbon Nanofibers for Tailoring Energy Storage Capabilities. Chemistry of Materials 27, 4574-4585, (2015).

47 Mao, X., Guo, F., Yan, E. H., Rutledge, G. C. \& Hatton, T. A. Remarkably High Heterogeneous Electron Transfer Activity of Carbon-Nanotube-Supported Reduced Graphene Oxide. Chemistry of Materials 28, 7422-7432, (2016).

48 Canongia Lopes, J. N., Deschamps, J. \& Padua, A. A. H. Modeling Ionic Liquids Using A Systematic All-Atom Force Field. J Phys. Chem. B 108, 2038-2047, (2004).

49 Kaminski, G. A. \& Jorgensen, W. L. Host-Guest Chemistry Of Rotaxanes And Catenanes: Application Of A Polarizable All-Atom Force Field To Cyclobis(Paraquat-P-Phenylene) Complexes With Disubstituted Benzenes And Biphenyls. J. Chem. Soc., Perkin Trans. 2 11, 2365-2375, (1999).

50 Canongia Lopes, J. N. \& Padua, A. A. H. CL\&P: A Generic And Systematic Force Field For Ionic Liquids Modeling. Theor. Chem. Acc. 131, 1129, (2012).

51 Canongia Lopes, J. N., Pádua, A. A. H. \& Shimizu, K. Molecular Force Field for Ionic Liquids IV: Trialkylimidazolium and Alkoxycarbonyl-Imidazolium Cations; Alkylsulfonate and Alkylsulfate Anions. The Journal of Physical Chemistry B 112, 5039-5046, (2008).

52 Price, M. L. P., Ostrovsky, D. \& Jorgensen, W. L. Gas-phase and liquid-state properties of esters, nitriles, and nitro compounds with the OPLS-AA force field. Journal of Computational Chemistry 22, 1340-1352, (2001).

53 Girifalco, L. A., Hodak, M. \& Lee, R. S. Carbon nanotubes, buckyballs, ropes, and a universal graphitic potential. Physical Review B 62, 13104-13110, (2000).

54 Plimpton, S. Fast Parallel Algorithms For Short-Range Molecular-Dynamics. J. Comp. Phys. 117, 1-19, (1995).

55 Tuckerman, M. E., Alejandre, J., Lopez-Rendon, R., Jochim, A. L. \& Martyna, G. J. A Liouville-Operator Derived. Measure-Preserving Integrator For Molecular Dynamics Simulations In The Isothermal-Isobaric Ensemble. J. Phys. A: Math. Gen 39, 5629-5651, (2006).

56 Hockney, R. W. \& Eastwood, J. W. Computer Simulation Using Particles. (Taylor\&Francis, 1988).

57 Ryckaert, J. P., Ciccotti, G. \& Berendsen, H. J. C. Numerical-Integration Of Cartesian Equations Of Motion Of A System With Constraints - Molecular-Dynamics Of n-Alkanes. J. Comp. Phys. 23, 327-341, (1977).

58 Siepmann, J. I. \& Sprik, M. Influence of surface topology and electrostatic potential on water/electrode systems. The Journal of chemical physics 102, 511-524, (1995).

59 Reed, S. K., Lanning, O. J. \& Madden, P. A. Electrochemical interface between an ionic liquid and a model metallic electrode. The Journal of Chemical Physics 126, 084704, (2007). 
$59360 \quad$ Wang, Z., Yang, Y., Olmsted, D. L., Asta, M. \& Laird, B. B. Evaluation of the constant potential method $594 \quad$ in simulating electric double-layer capacitors. The Journal of Chemical Physics 141, 184102, (2014). 
a

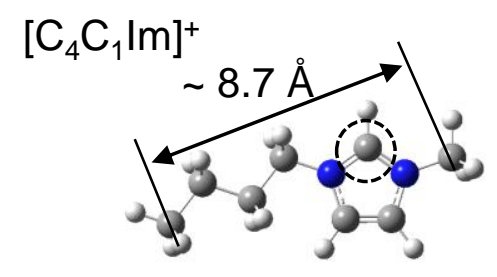

[AOT]-

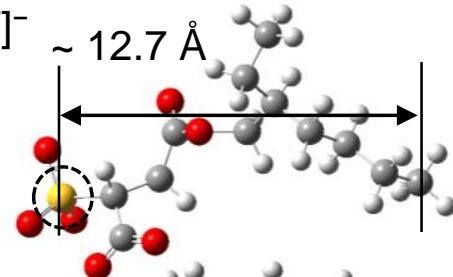

$\left[\mathrm{BF}_{4}\right]$

$\sim 1.4 \AA$

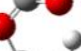

83900

-

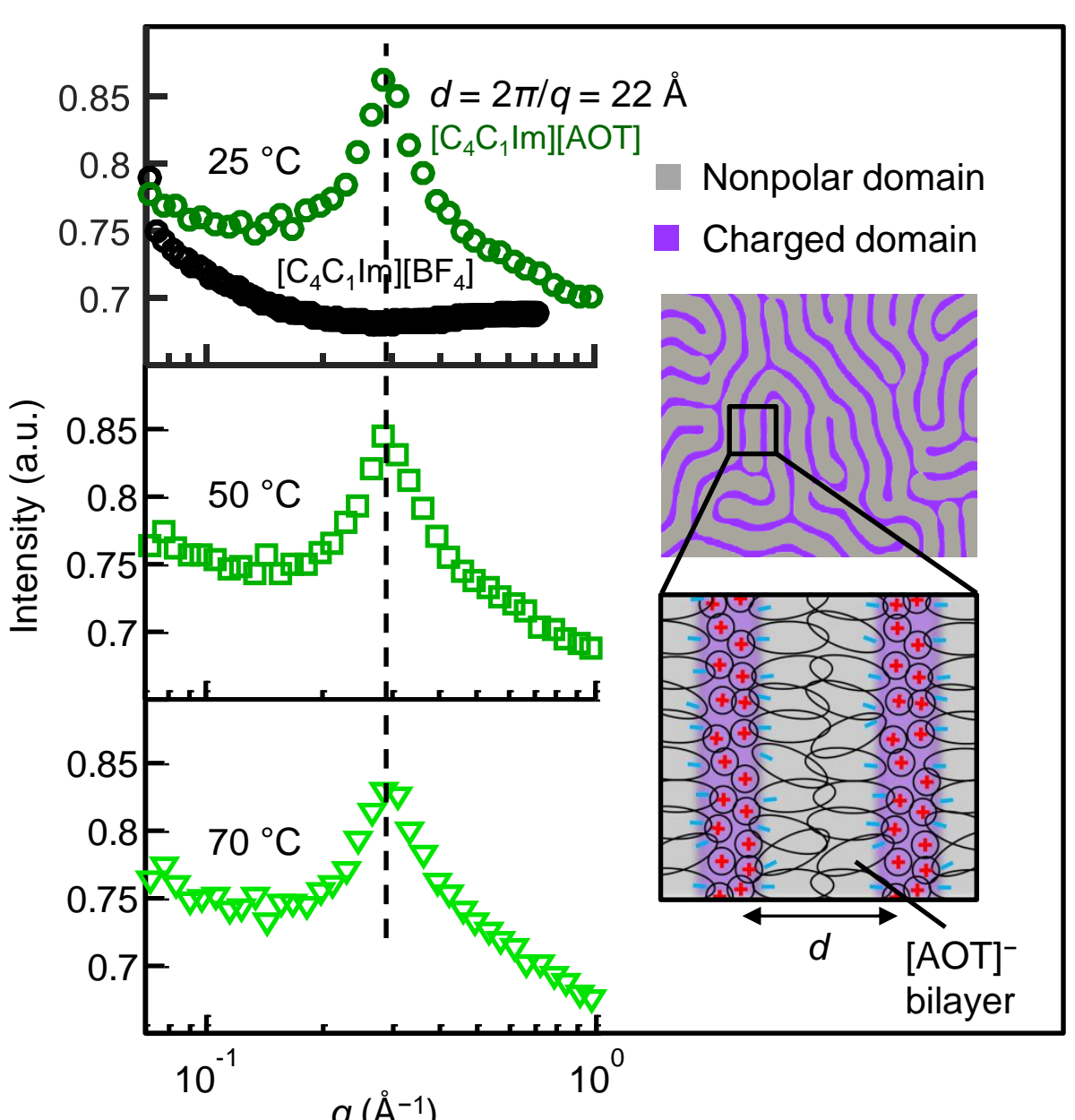

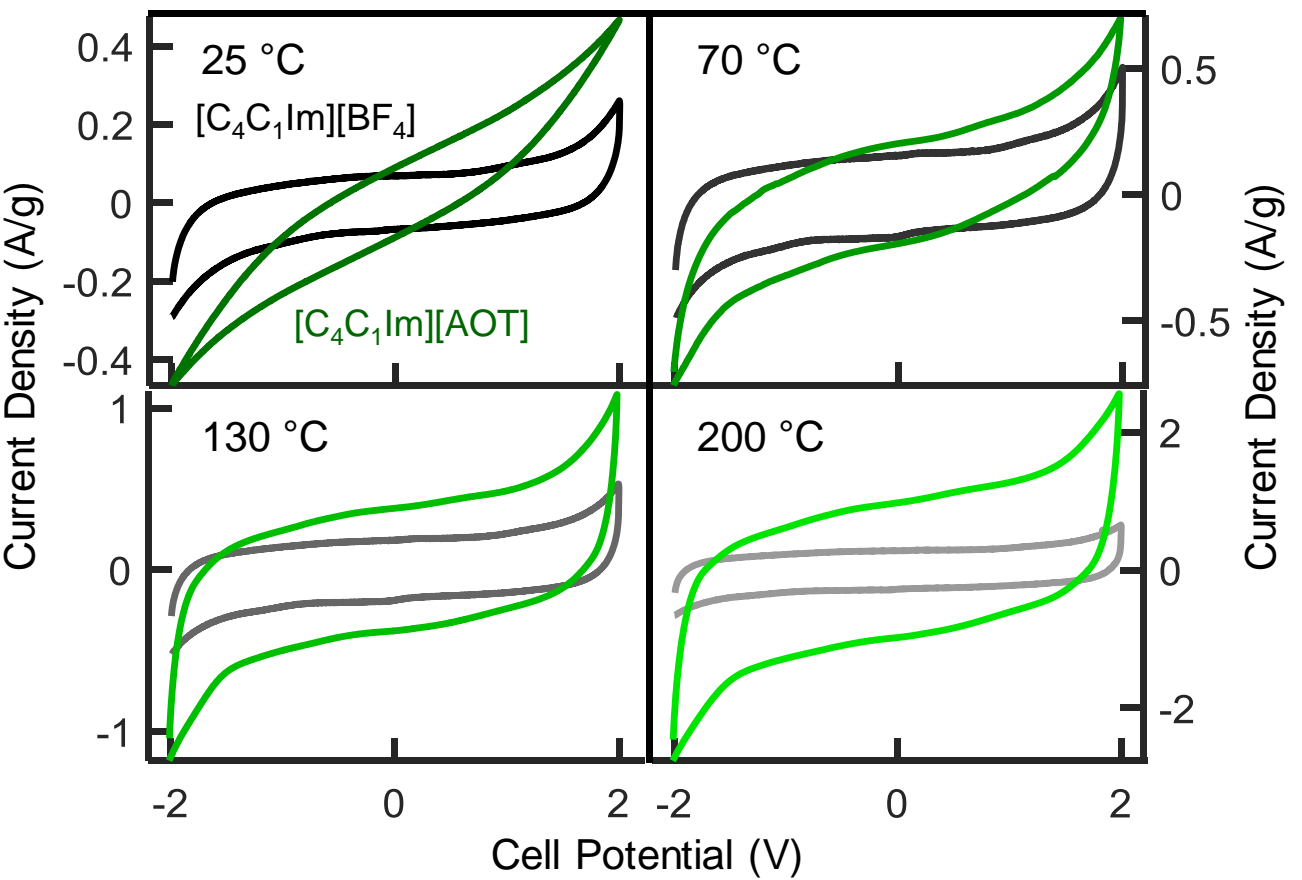

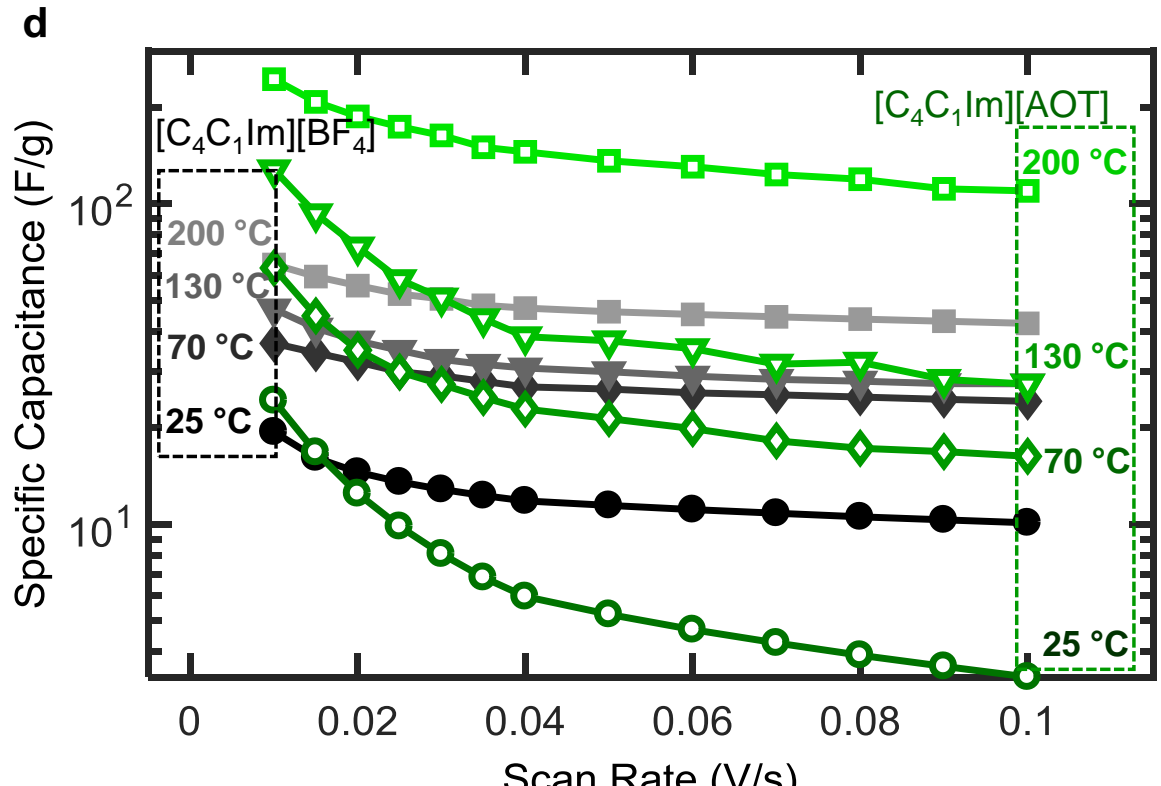


Distance from Electrode $(\AA)$

b

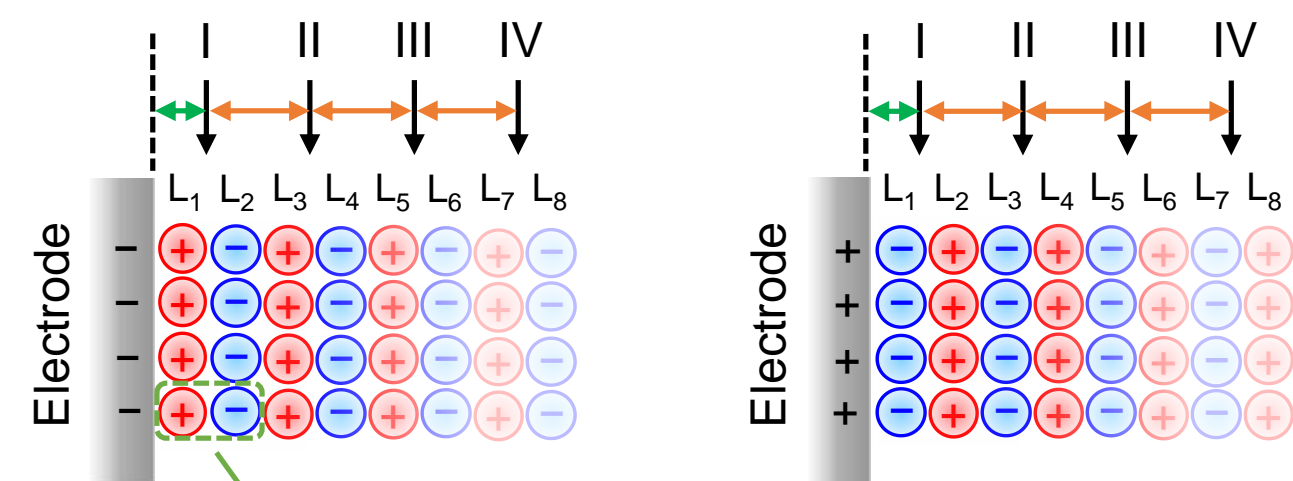

Neutral Aggregate

C

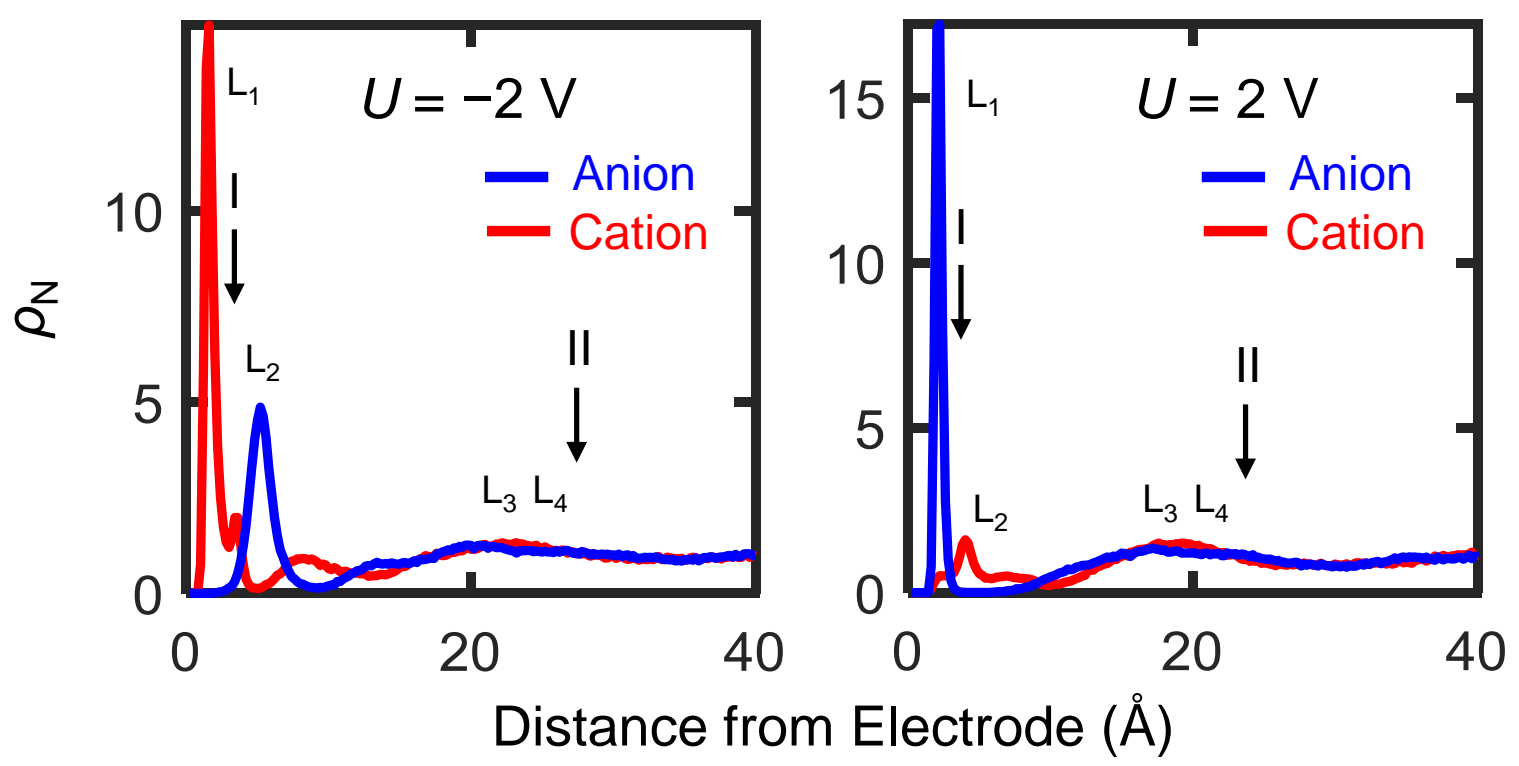

f
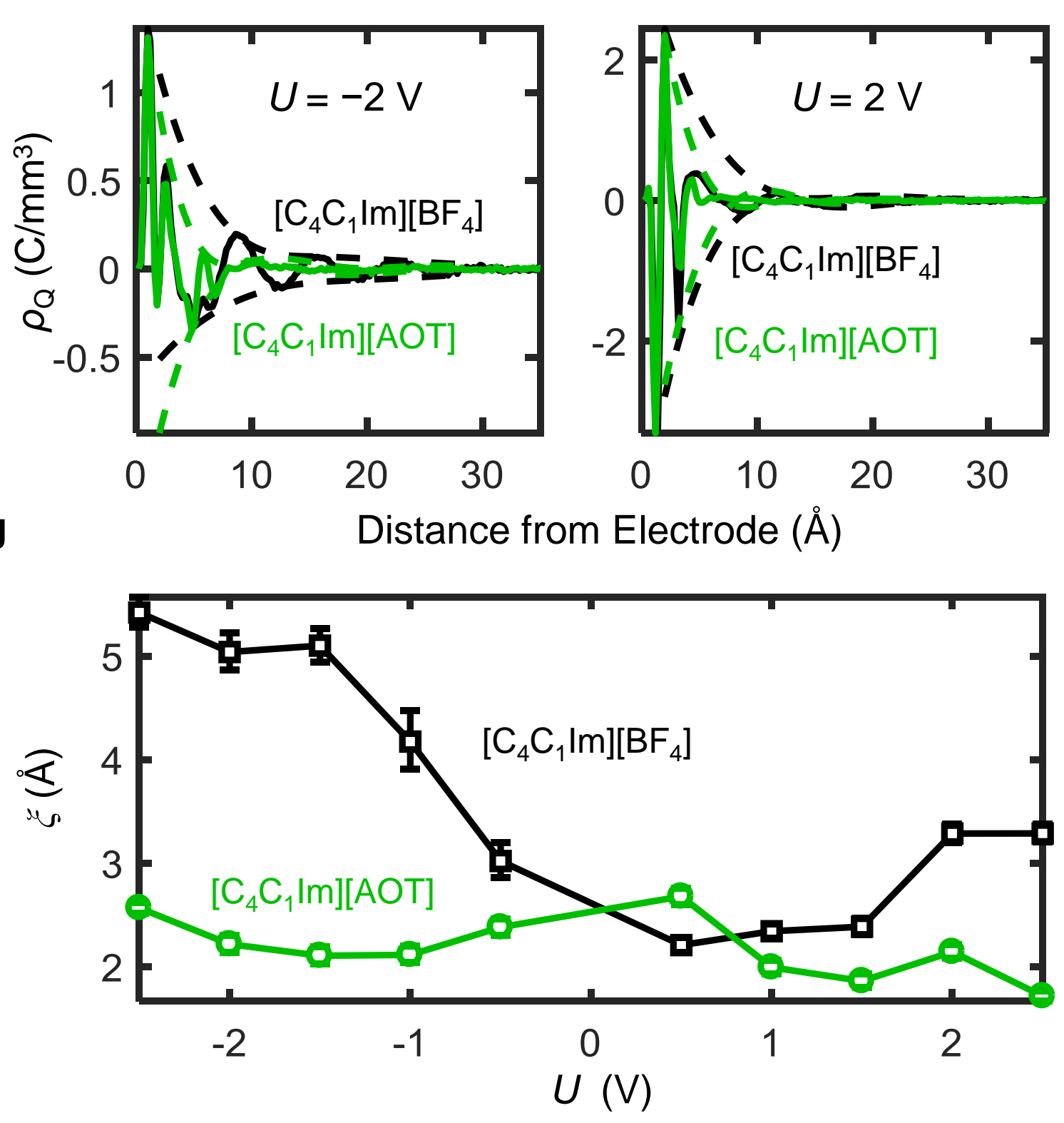

h

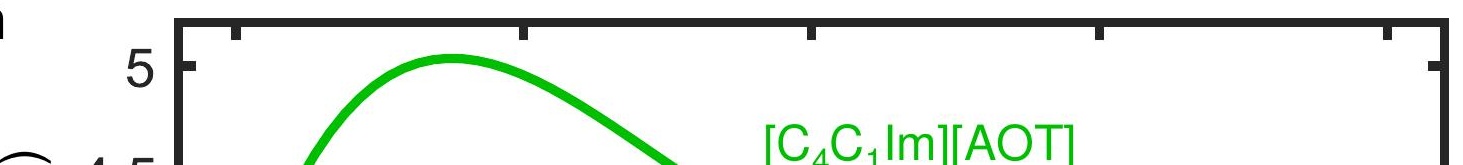


a

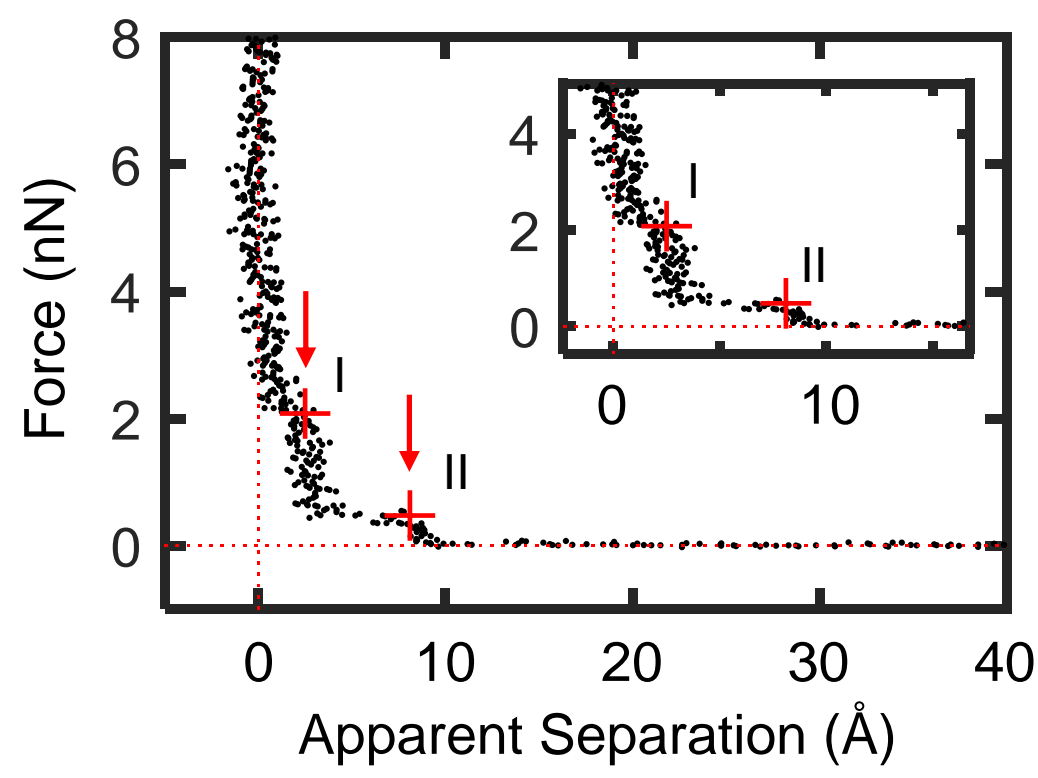

d

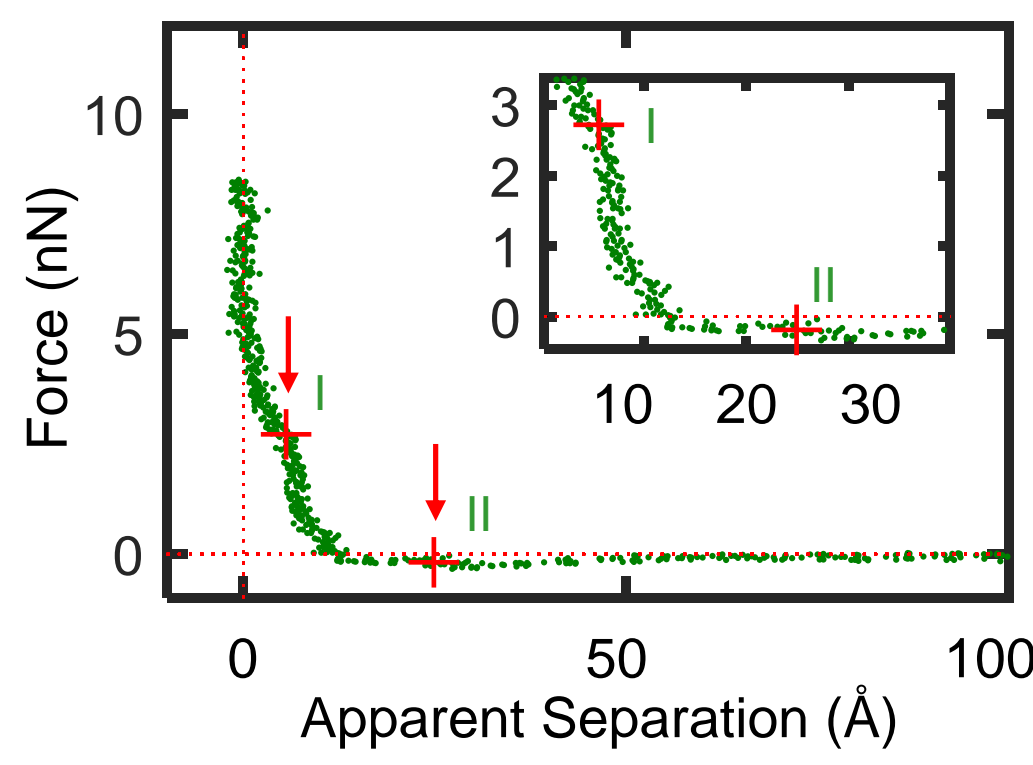

b

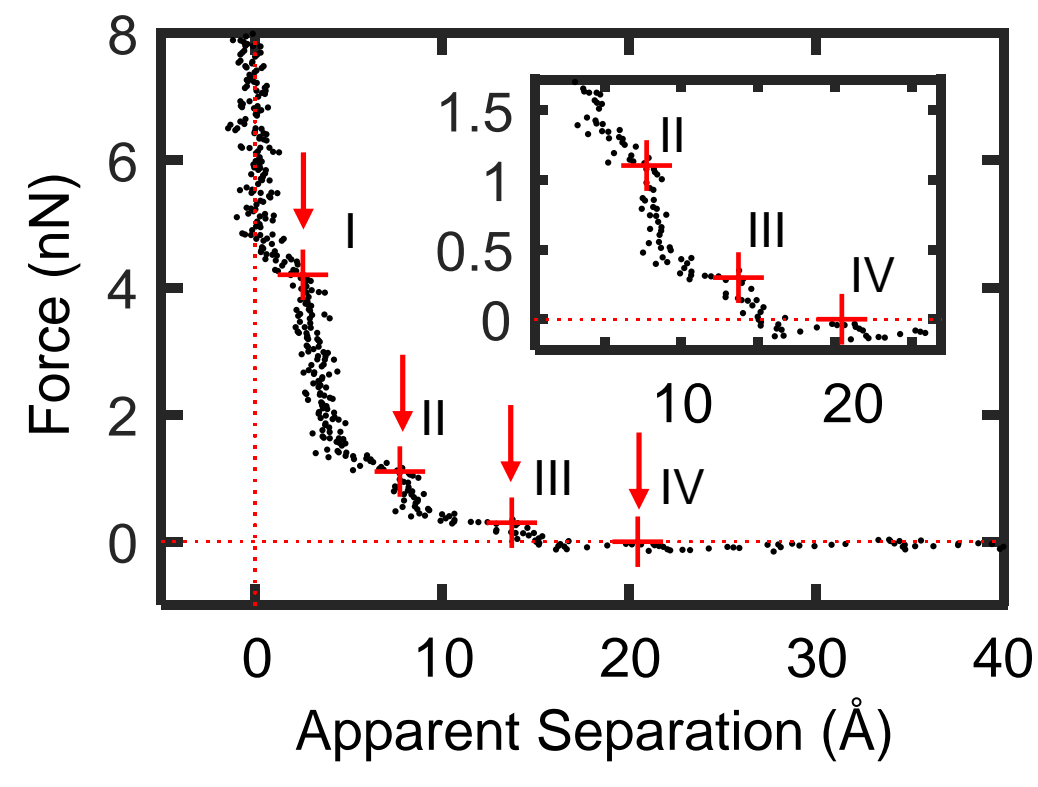

e

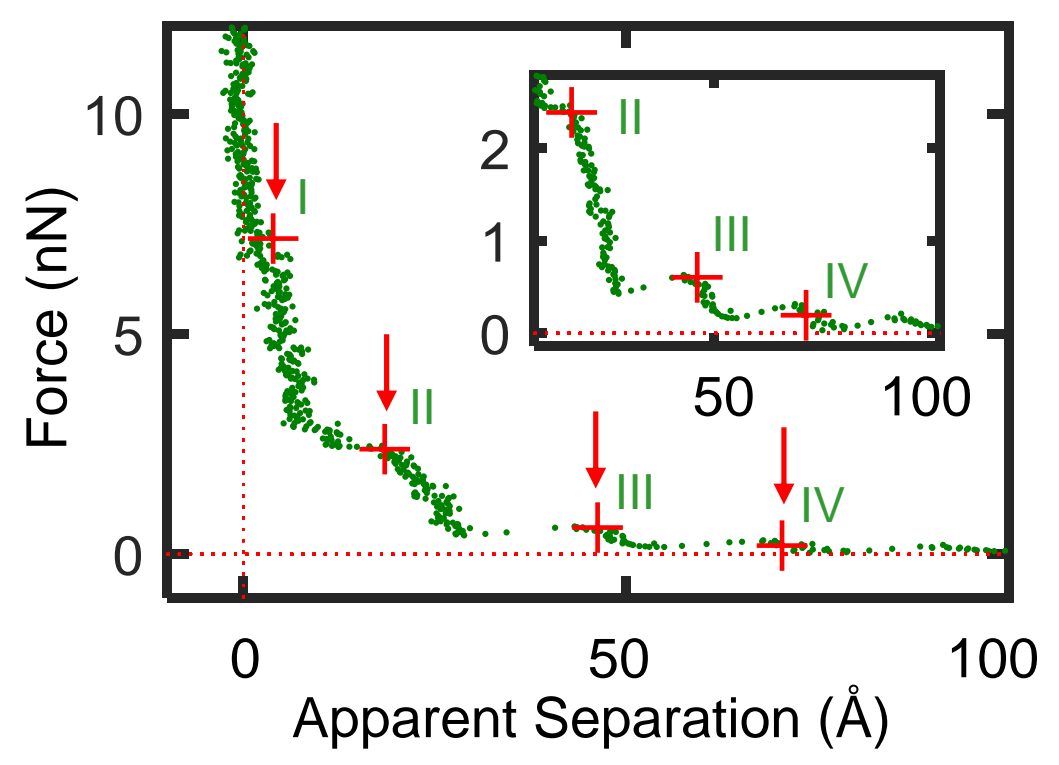

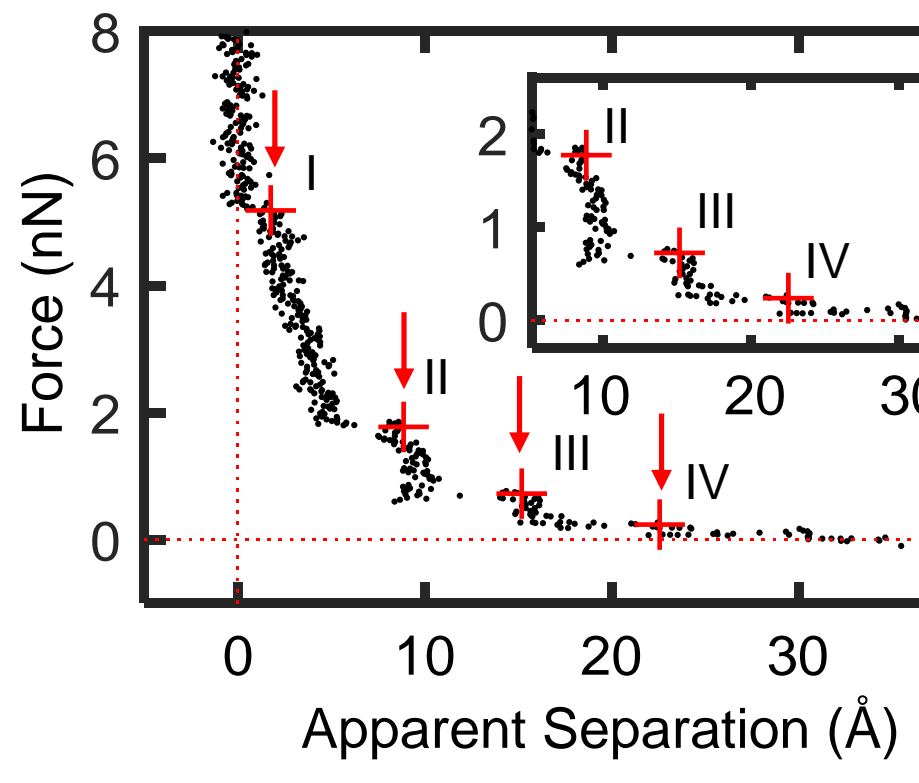

f

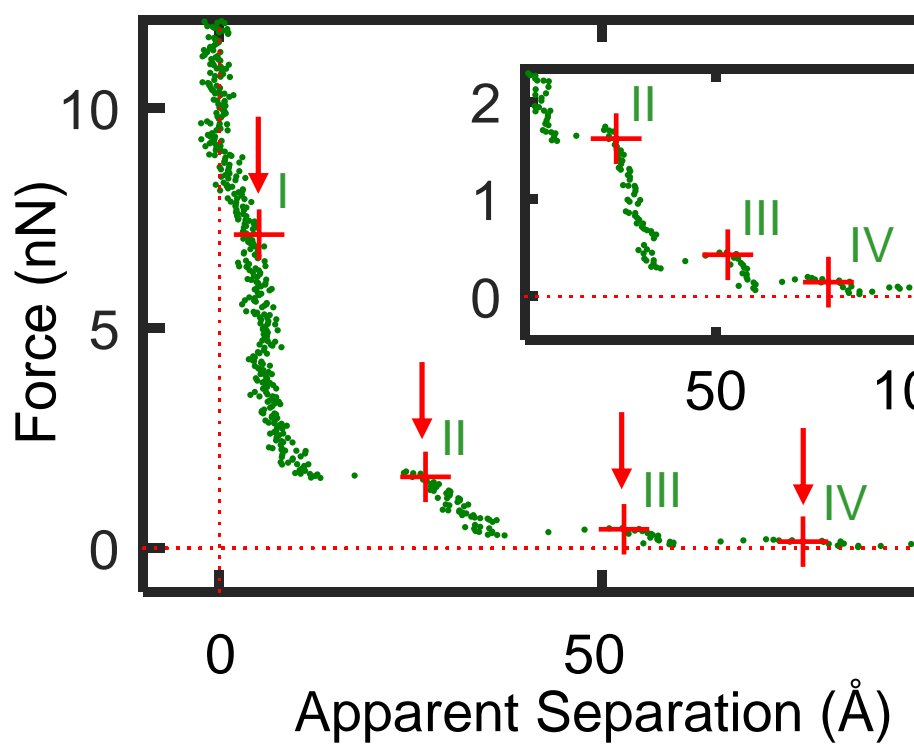



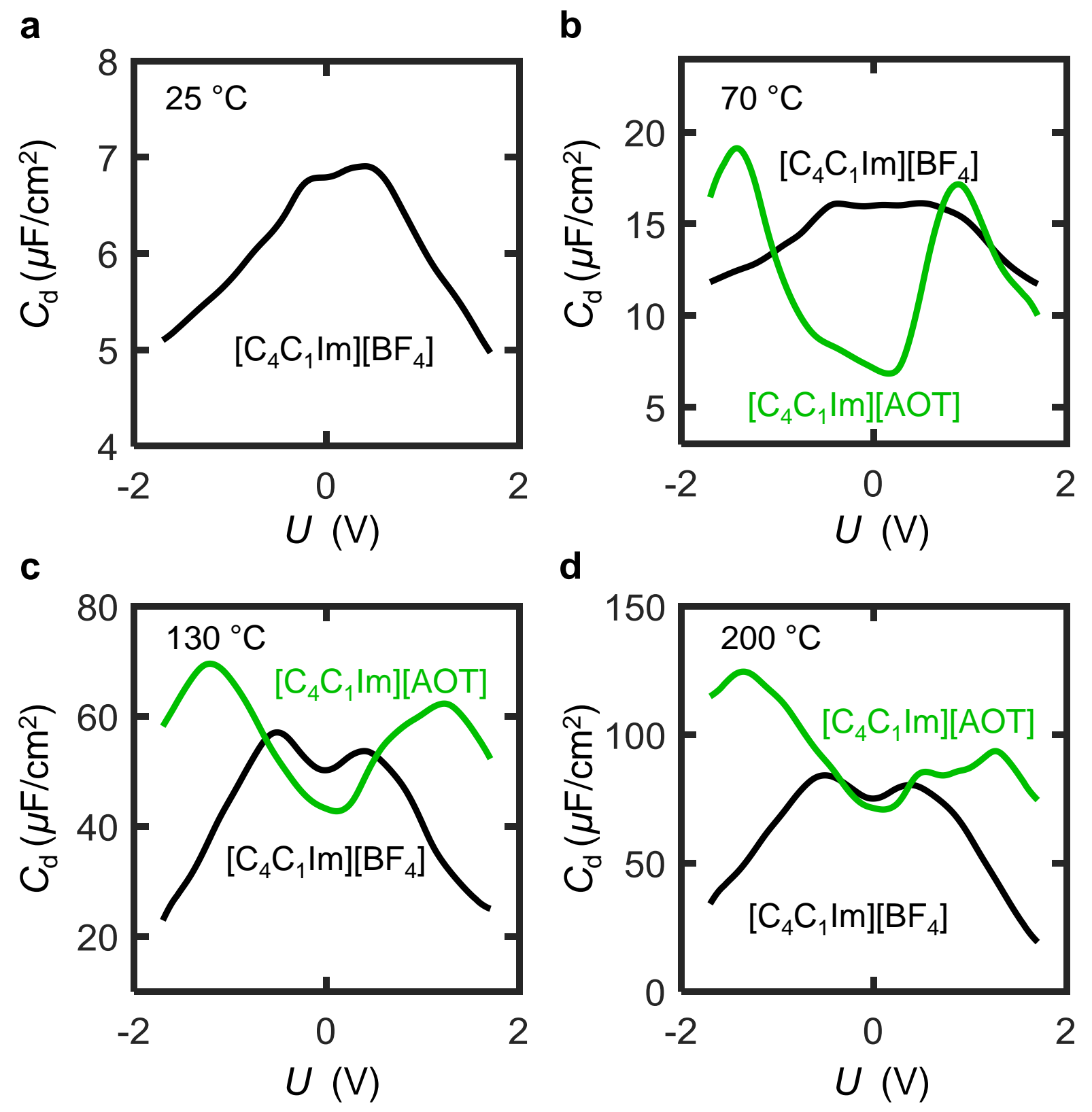
a
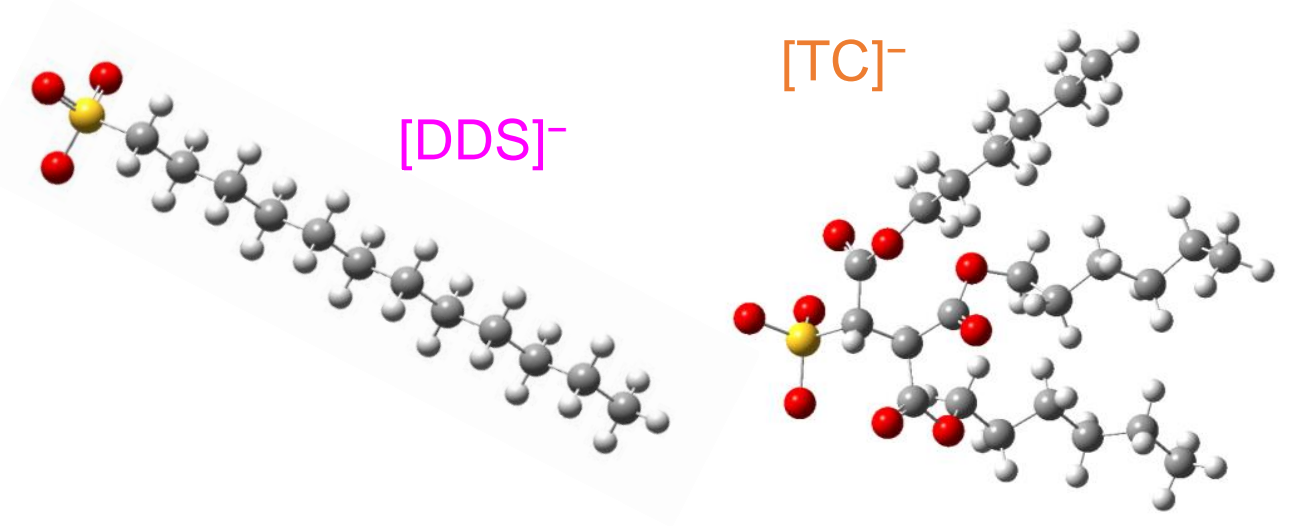

b

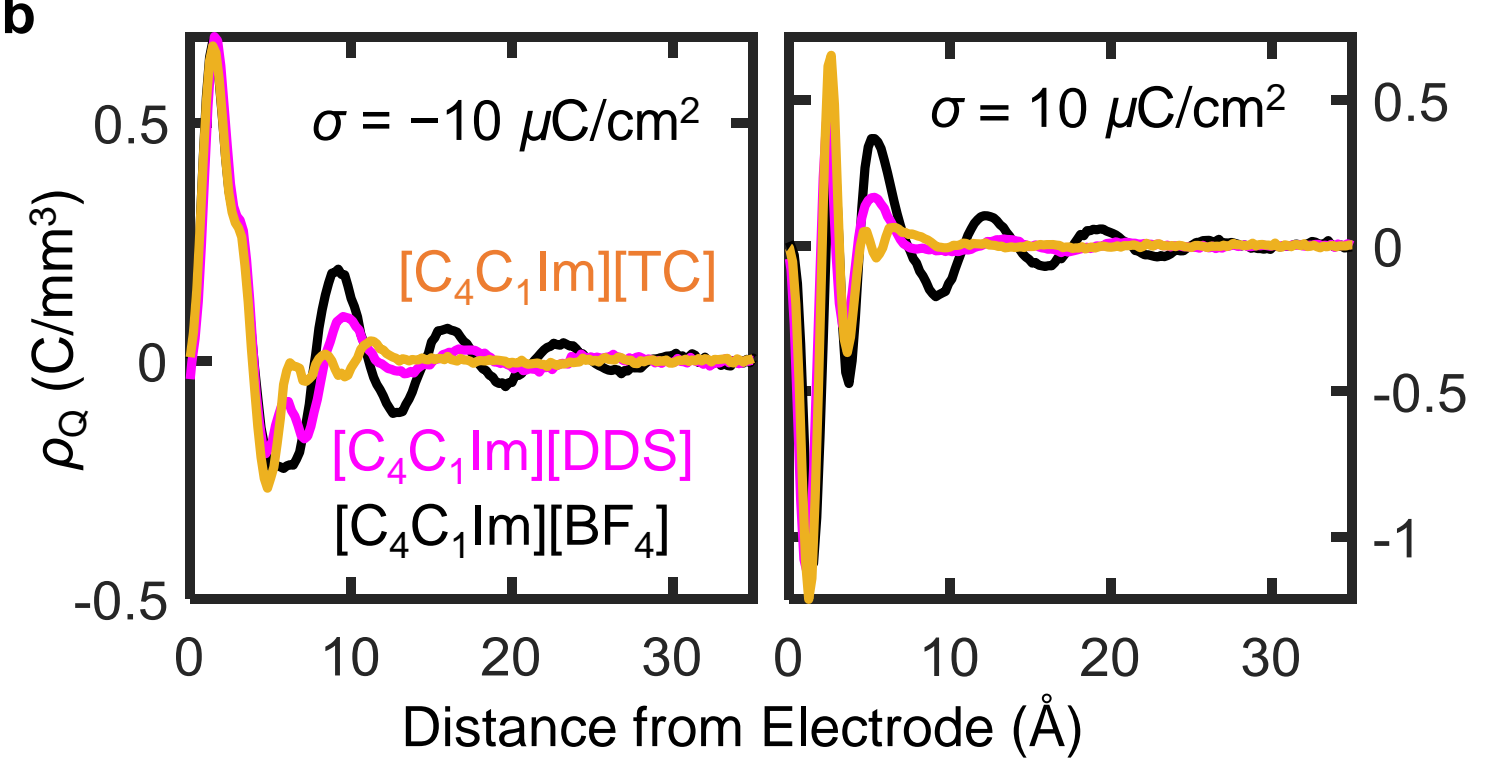

C

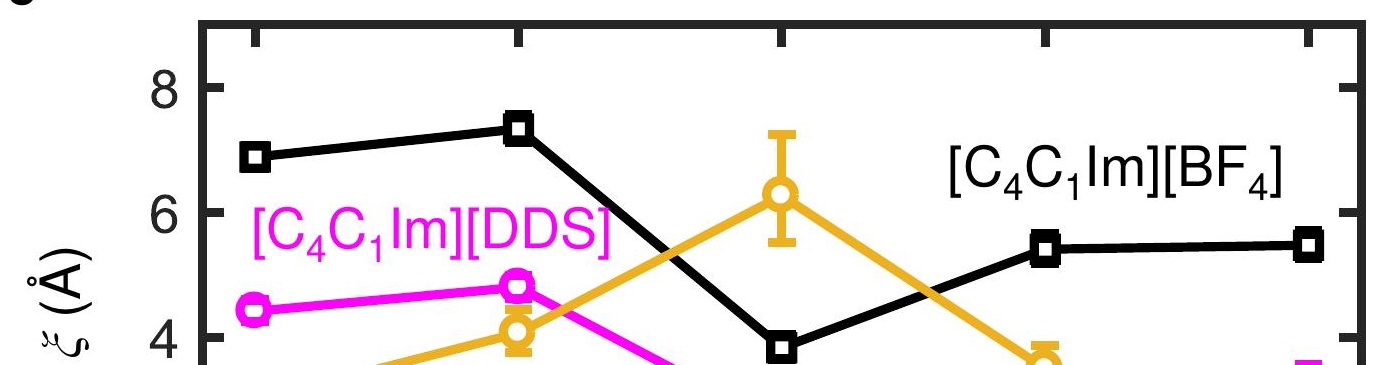

d

Low Temperature

High Temperature

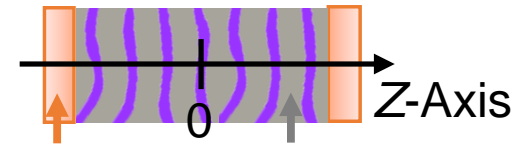

$\stackrel{v_{0}}{ }$ Z-Axis

Confining Nonpolar

Surface Domain

e

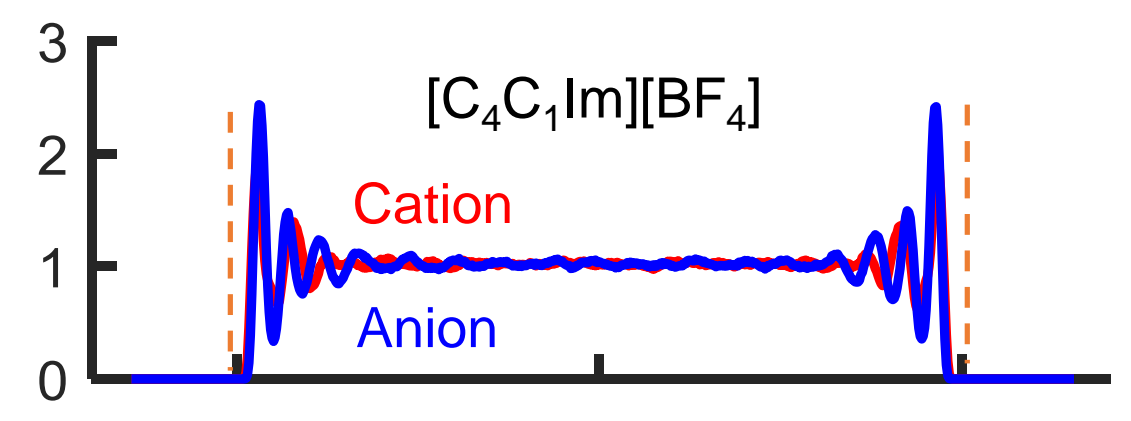

2
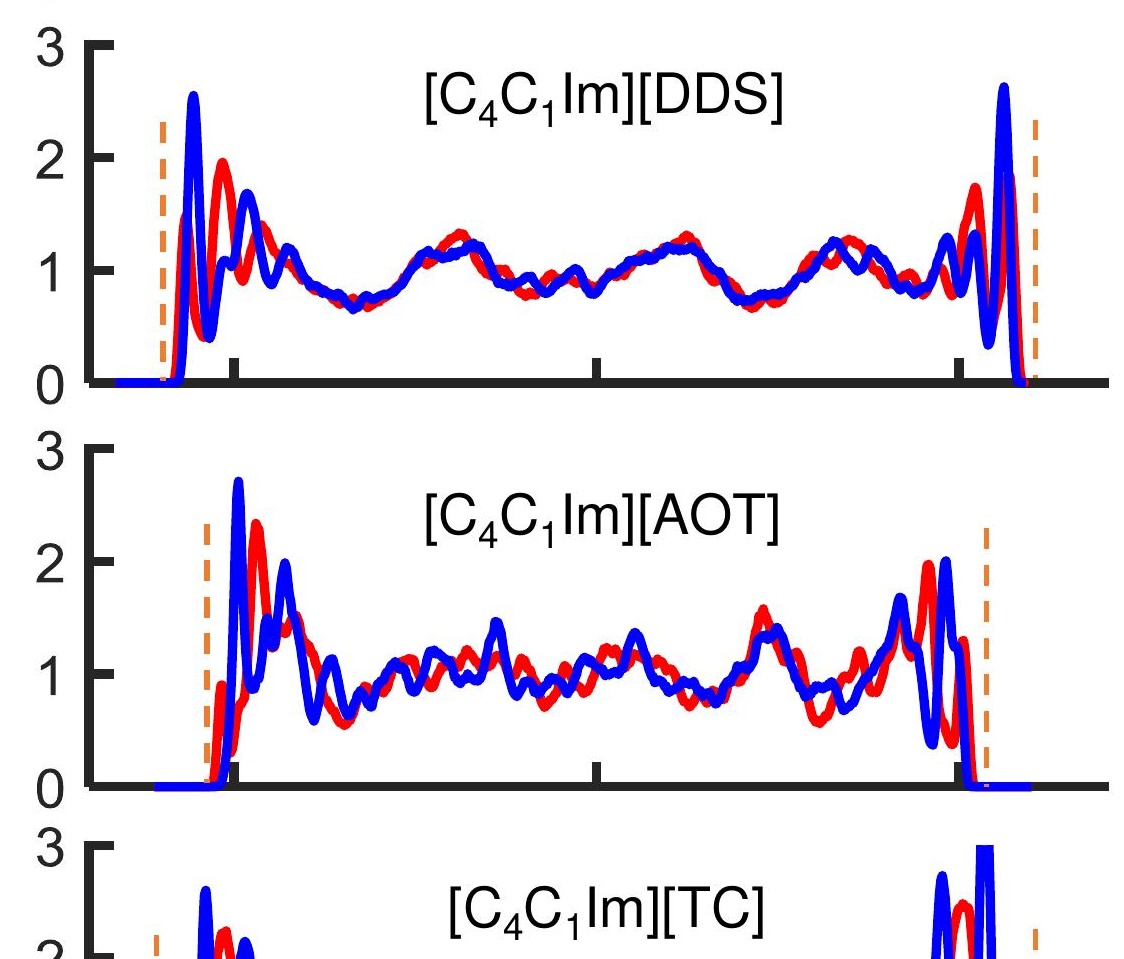
a
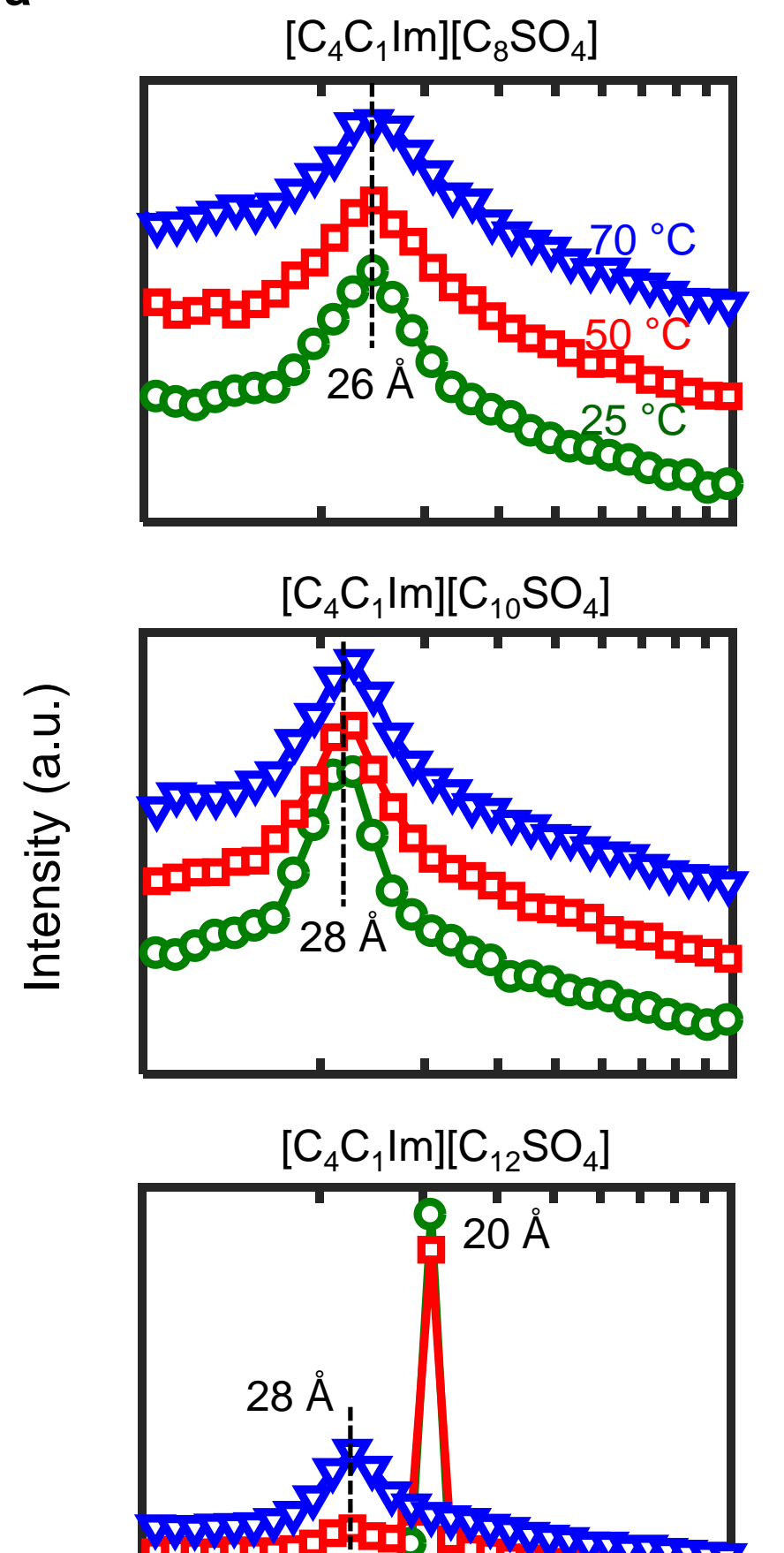

b

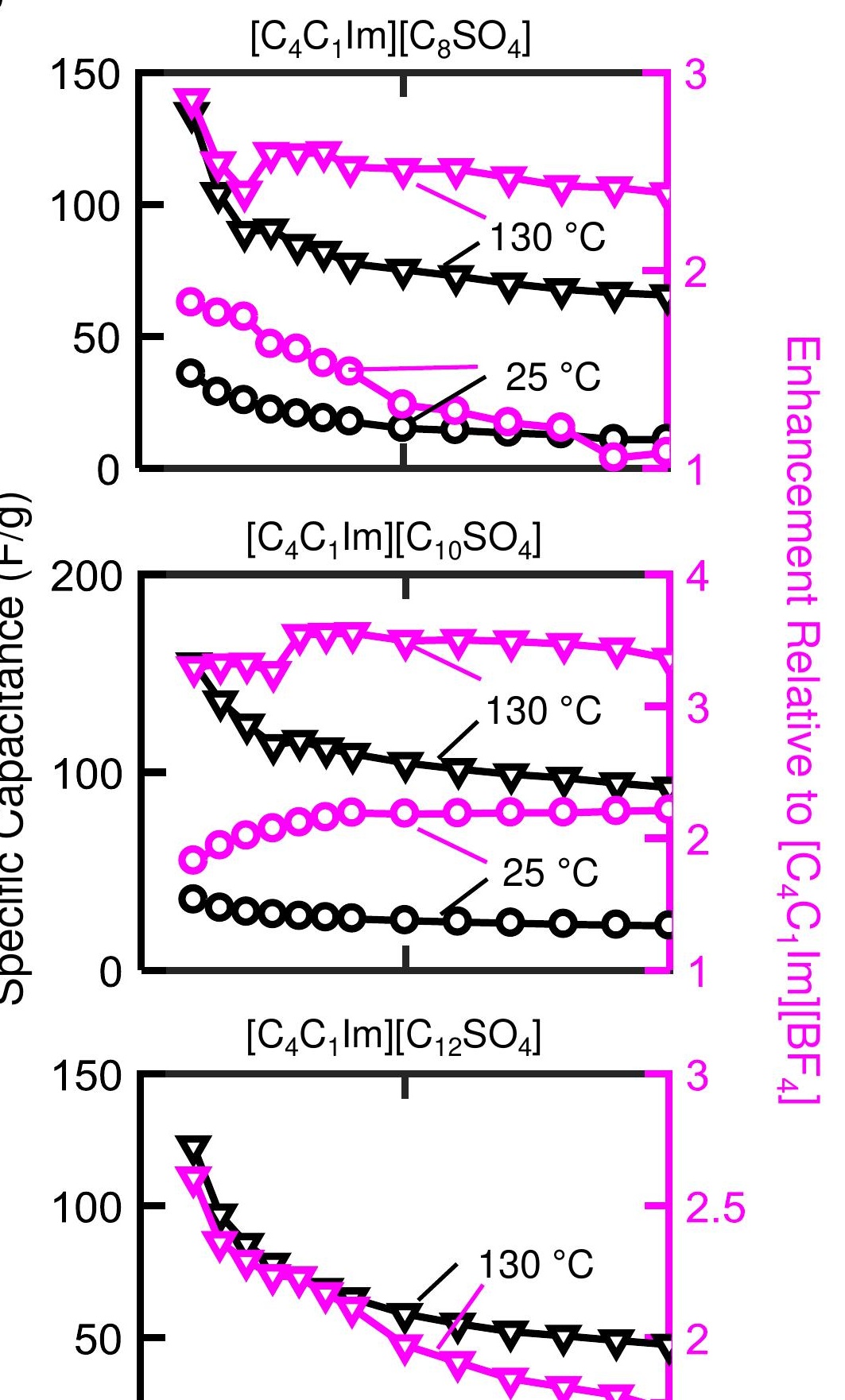

